\title{
COMMUNICATIONS
}

\section{REVIEW OF 555 CASES OF INTRA-OCULAR FOREIGN BODY WITH SPECIAL REFERENCE TO PROGNOSIS $\dagger^{*}$}

BY

\author{
M. J. ROPER-HALL \\ Birmingham
}

INTEREST in cases of intra-ocular foreign body often centres in the drama of the operation and the "spirit of triumphant success" when the foreign body is removed. It must be remembered, however, that the matter does not end there (Duggan, 1933; Cridland, 1933; Kiehle, 1932), and that the final result may not justify the early jubilation. In the literature on methods of treatment and their advantages we find many subjects of considerable controversy and seeming prejudice; for instance, one surgeon or hospital insists that all removals should be attempted by the anterior route, while another surgeon champions the posterior route; each reports a series in which almost all the cases are dealt with by one or other procedure, and neither appears to have any experience of the opposed method.

It also becomes clear that reviews of this nature on civilian cases in Great Britain deal with rather small series. One which was made as long ago as 1908 is still regarded by some as the authoritative work on the subject, though the conclusions are based on findings which no longer apply. Since the beginning of the 20th century many series have been reported of military cases in which the problems are very different, as will be seen later.

\section{PRESENT InVESTIGATION}

In this series of 555 cases it has been found possible to substantiate certain facts; solutions to some problems are offered, and new problems appear to be raised. The study has limitations, in particular because the notes on which it is based were seldom as complete as could be wished, but it may form a basis from which to plan future surveys of the whole subject of the intraocular foreign body.

Material.-Cases of corneal and scleral foreign bodies are excluded unless a penetration occurred, and orbital foreign bodies following double perforation are also excluded. Thus all cases included are ones in which a foreign body became lodged within the eye.

The records are derived from the case notes of patients treated in the operating theatres of the Birmingham and Midland Eye Hospital between the years 1932 and 1951 inclusive. Some case sheets, particularly those referring to patients treated during the war years, were not found. The number of cases in each year, allowing for those in which the records could not be found, varied from 22 in 1938 to 54 in

\footnotetext{
+From a thesis presented for the Degree of Ch.M., University of Birmingham, December, 1952.
} *Received for publication June 27, 1953. 
1946. There appears to be no definite increase except between 1942-46, when the employment of untrained workers on account of the absence of skilled workers in the forces, the use of materials possibly of lower standard, and the difficulty of replacing faulty tools would appear to offer an explanation. The average number of cases per year over the whole period is assessed at $35 \cdot 3$, and during the years 1942-46 inclusive at $39 \cdot 8$.

Excision.--The proportion of cases requiring excision has shown a more definite variation (Fig. 1); a considerable reduction has been achieved with the passage of time. The highest level was $43 \cdot 5$ per cent. in 1933 and the lowest $6 \cdot 25$ per cent. in 1936. Another low reading ( 7 per cent.) is found in 1943. A grouping of the figures given in Fig. 1 into 5-year periods shows a gradual drop in the excision rate from 29.8 per cent. in the first period to 22.9 per cent. in the second period, $17 \cdot 3$ per cent. in the third period, and $14 \cdot 2$ per cent. in the fourth period. This improvement appears to be largely the result of better control of infection. Among the 111 excisions in the whole series, 37 eyes were excised because of panophthalmitis, and definite infection was present in seven other cases. Thirteen cases of panophthalmitis occurred in the first period of 5 years, eight in the second, seven in the third, and three in the fourth. In the years 1932-35 this was the greatest single cause of excision, but more recently it appears to be of relatively minor importance. There was a sudden increase in 1939 and 1940, for which I can offer no explanation. Cridland (1933) quotes relevant articles from 1906 to 1930 , in which the excision rate varies from 51 to 32 per cent.

This trend in the number of excisions has, therefore, also been noticeable in other comparable series (Barkan and Barkan, 1927, 18 per cent.; Duggan, 1933, 26 per cent.; Trevor-Roper, 1944, 18 per cent.; McBride, 1949, 20 per cent.; Sellas, 1949, 13 per cent.). In the remaining literature it is surprising how often no figure is given of the
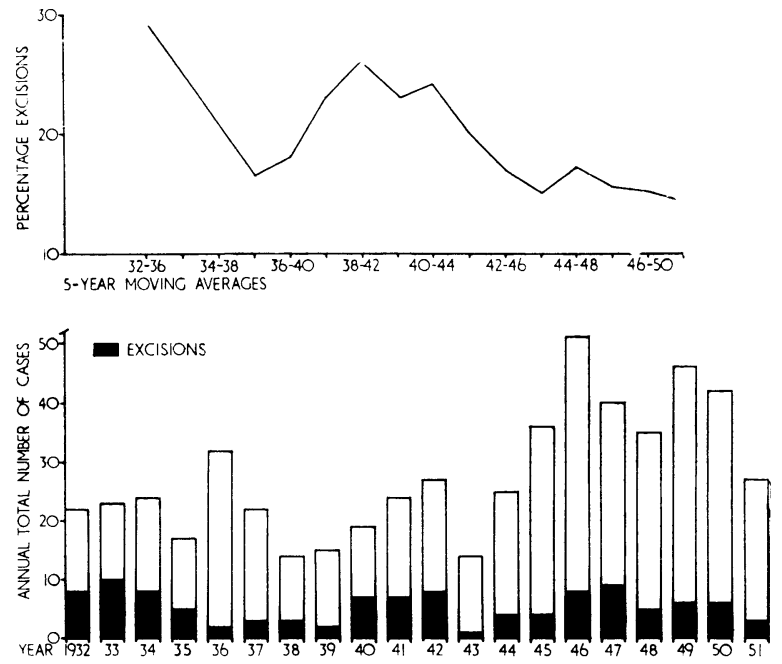

FIG. 1.-Annual total numbers of cases and numbers of excisions, 1932-51. The percentage excisions are shown above in 5-year moving averages from 1932-36 to 1947-51. number of excisions performed, and these are grouped with the cases of less than $6 / 60$ final vision, or in the even more vaguely expressed category of "poor results" or "loss of vision".

Age of Incidence.-As is to be expected with trauma, especially in an industrial

TABLE I

AGE OF INCIDENCE

Age Group (yrs) No. of Cases

$\begin{array}{rr}\text { under }-10 & 7 \\ 11-20 & 58 \\ 21-30 & 211 \\ 31-40 & 154 \\ 41-50 & 81 \\ 51-60 & 30 \\ \text { Over } 60 & 14\end{array}$

community, the greatest number of cases (365) occurred between the ages 21-40 (Table I). These cases show the highest incidence of magnetic foreign bodies, and the great majority were the result of the patient's own action. 
During the war a higher average age is noted because of the absence in the armed forces of most of those of call-up age. Of the fourteen cases in patients over 60 years of age, all but one were industrial accidents and half occurred between 1941 and 1946. An increase was also seen in the 11-20-year group during the war.

In the group under 10 years of age, on the other hand, only seven cases occurred. Most of those patients may be classified as spectators: one was hit by a piece of wood which was being chopped, a second by the branch of a tree, and a third by glass (the boy's spectacles having been broken by a thrown brick); the remaining four were hit by magnetic fragments, one while watching a pneumatic drill at work in the street. Thus three out of the seven foreign bodies in this small group were non-magnetic.

Cause of Injury.-Many authors have drawn attention to the use of hammer and chisel as the commonest cause of injury in civilian cases. McBride (1949), reporting fifty cases in Los Angeles, states that striking a king-pin with a hammer ranks highest as the source of injury, and puts the hammer and chisel second.

In the present series, the recorded history in many cases is limited to " hit by piece of steel in L (or R) eye at work this morning ". In such cases the circumstances of the injury could not be checked, except in the few which could be contacted for follow-up examination. In 214 cases the history is more complete; 65 of them (30.4 per cent.) were due to the use of hammer and chisel, and a further 91 (42 per cent.) occurred while a hand hammer was being used for other purposes. Here the king-pin is found, but no more frequently than the wedge, punch, die, chain, rivet, rawlplug tool, spanner, screwdriver, or sheet of metal. Hand hammer injuries thus account for 73 per cent. of the foreign bodies in this series. Injuries from machine tools are much less frequent; there are 39 cases (18 per cent.) exactly onethird of which were caused by the breaking of a drill when two pieces of hardened and brittle steel came forcibly into contact.

Six cases were the results of explosions, e.g., an old grenade injury in a demobilized man, a dust-bin explosion, and an explosive incendiary bomb.

In the remaining thirteen cases the causes were unusual: three patients were hoeing in garden or field when they were struck by what was thought to be a stone but proved to be a magnetic foreign body. Only one case occurred in a miner who was striking coal with a pick. The case of the boy watching road work and that of the boy whose spectacle lenses were broken have already been mentioned. Two cases occurred when the patient was walking down a gangway through the works. Two men were cutting steel at the time of the accident, and one was engaged in welding.

It is possible that these unusual causes appear falsely in higher proportion because they were likely to have their history recorded in more detail, but, on the other hand, a similar proportion of the remaining patients whose history is inadequate were unaware of any injury having occurred. Such injuries are sometimes almost painless (in sharp contrast to the superficial corneal foreign body), and should they occur during the course of some action in which injury is most unexpected, as in hoeing or walking through the works, it would seem quite possible that no history would be obtainable when the patient attended subsequently because of some complication.

Magnetic Response.-As is to be expected from the type of injury, a high percentage of the foreign bodies in this series ( 89 per cent., 483 cases) were magnetic; 8 per cent. ( 45 cases) were non-magnetic and 3 per cent. ( 17 cases) were not proved.

This corresponds closely to the figures given in other civilian series (Sherman, 1939, 93 per cent.; Duggan, 1933, $90 \cdot 6$ per cent.; McBride, 1949, $93 \cdot 7$ per cent.; Sellas, 1949, 90 per cent.), except that of Allport $(1925,99 \cdot 5$ per cent.). 
It was suggested by Kraus and Briggs (1945), writing in favour of the posterior route of removal, that an increase in the number of non-magnetic foreign bodies could be expected in civilian practice, in view of the increased use of non-magnetic alloys. To test this theory, the cases in the present series were divided into four 5-year groups, and the incidence of non-magnetic foreign bodies was then found to be as follows: $1932-36,7$ per cent.; $1937-41,6 \cdot 5$ per cent.; $1942-46,9$ per cent.: 1947-51, 9 per cent.

The 3 per cent. (seventeen cases) not proved comprise the following:

Three cases where the foreign body was removed in the lens by cataract extraction;

One with a perforating corneal foreign body removed without the magnet;

Four where the foreign body was removed with forceps;

Nine foreign bodies retained.

Of the 45 non-magnetic bodies, twenty were not identified, but are stated to be non-magnetic with good reason (by seeing the foreign body when the magnet was applied, by repeated attempts to remove it, or by pathological examination of the excised eye). In the remaining 25 cases, nine foreign bodies were brass, four wood, three stone, two aluminium alloy, and one each zinc, tin*, manganese*, nickel, glass, lead, and hair (an eyelash).

In over half of these 45 cases (26) the foreign bodies were retained; seven of these eyes were excised and the visual acuity of the remainder when last taken was less than $6 / 60$ in two cases, 6/60-6/24 in five, 6/18-6/9 in six, and $6 / 6+$ in five, one being not known.

In this group a short follow-up period is likely to give a false impression of the prognosis; however, by limiting our consideration to cases followed up for more than one year, we find the following seven results as regards visual acuity:

Less than $6 / 60$, one $6 / 60-6 / 24$, one; $6 / 18-6 / 9$, two $; 6 / 6+$, three cases ( 43 per cent.). These visual results are better than for the series as a whole in cases followed-up for more than one year (less than $6 / 60,42 ; 6 / 60-6 / 24$, seven; 6/18-6/9, 31; 6/6+, 35 cases; 30 per cent.). A higher percentage, however, was excised ( 27 per cent.).

The visual acuity of the nine patients with retained foreign bodies of doubtful magnetic properties do not show the same retention of useful vision as those just tabulated: six have less than $6 / 60$; one has $6 / 60-6 / 24$; three have $6 / 18$ to $6 / 9$; none have $6 / 6+$. This is strongly suggestive of a high proportion of iron or steel causing lowered visual acuity by siderosis of the retina. None of these cases has clinically demonstrable sideroșis elsewhere.

A bad prognosis is usually given in cases where the foreign body is composed of brass or copper (Gray Clegg, 1915; Whitehead, 1916; Würdemann, 1932; Sellas, 1949). The large number of copper foreign bodies in Sellas' series was due to the explosion of inefficiently emptied cartridges brought back to the foundries. This fact must be remembered, when considering his results, because the type of injury is such as to make the prognosis relatively worse than with the usual civilian injury. In view of this poor prognosis, a more detailed study of the nine cases of brass foreign bodies was felt to be justified (Table II, opposite): three were successfully removed, two with useful vision retained; six were retained; three eyes were later excised because of pain, blindness, and infection, but of the remaining three, two appear to have retained usefulvision. Thus, on this admittedly small series, the outlook does not appear to be greatly worse than with magneticforeign bodies, although the severity of the inflammation when it does occur is very striking.

There is, of course, a potential danger of late complications in the cases with retained foreign bodies. It would seem, however, that, if the eye is free from infection during the early period after the accident, the prognosis is not necessarily serious. 
TABLE II

BRASS OR COPPER FOREIGN BODIES

\begin{tabular}{c|l|l|l|l}
\hline Case No. & Fate of Foreign Body & $\begin{array}{c}\text { Position of Foreign } \\
\text { Body }\end{array}$ & Visual Result & $\begin{array}{l}\text { Length of } \\
\text { Follow-up }\end{array}$ \\
\hline 1 & Retained & Vitreous & Excised & $*$ \\
2 & Retained & Nerve head & Excised & $*$ \\
3 & Retained & Lens & Excised & $*$ \\
4 & Retained & Lens & $6 / 12$ & $3-6$ mths \\
5 & Retained & Vitreous & $6 / 18-6 / 9$ & $1-2$ yrs \\
6 & Retained & Retina & Less than $6 / 60$ & Over 2 yrs \\
7 & Removed & Sclera & Less than 6/60 & Over 2 yrs \\
8 & Removed & Iris & $6 / 6+$ & $1-2$ yrs \\
9 & Removed & Anterior chamber & $6 / 18-6 / 9$ & $6-12$ mths \\
& & & & \\
\hline
\end{tabular}

*All three excisions were done early for painful, infected, and blind eyes.

\section{Size of Foreign Body, Side Involved, and Type of Injury.}

Size.-This must be expected to be one of the most important factors in the prognosis. The larger foreign bodies will cause more severe damage both on entry and removal, while the smaller ones may cause little damage and are less likely by their momentum to have penetrated deeply.

Special consideration of size is given by many authors, including Morax (1917), Morax and Moreau (1917), Shoemaker (1919), Sherman (1939), Stallard (1947), Bellows (1947), and McBride (1949). It is interesting that these authors concern themselves mainly with the largest dimension; if they go any further it is to include one more dimension (Allport, 1925; Bellows, 1947), but except in reporting individual cases the third dimension is omitted. Consideration should be given to the volume of the foreign body as well as its greatest dimension. To regard the foreign body as two dimensional does not serve a useful purpose.

The weight of the foreign body is of considerable importance as shown by Morax and Moreau (1917), but theirs cannot strictly be compared with other series where only size is mentioned because of the variation in weights of different materials.

In the present series, figures for maximum diameter are compared with the series of Stallard (1947); these show that the military intra-ocular foreign bodies are on the average smaller than the civilian ones. Comparing the figures taken from Stallard, 20 per cent. of foreign bodies in the present series are less than $2 \mathrm{~mm}$. in greatest diameter (Stallard, 40 per cent.); 45 per cent. are less than $3 \mathrm{~mm}$. (Stallard, 67 per cent.); 76 per cent. are less than $5 \mathrm{~mm}$. (Stallard, 86 per cent.).

The size of foreign body was not recorded in every case in the present series, but is known in 89-almost all of which refer to the last 3 years, so that the excision rate is rather lower (15 per cent.) than in the whole series.

Table III (overleaf) shows the sizes in c.mm. in these 89 cases. It can be seen that the excision rate increases with the size of the foreign body. It is also interesting to notice that for foreign bodies of less than $2 \mathrm{c} . \mathrm{mm}$. the incidence of cataract preor post-operatively is the same. As the size of the foreign body increases above this, the number of post-operative cataracts shows an increase over the pre-operative figure amounting to almost twice that seen with foreign bodies of more than $16 \mathrm{c} . \mathrm{mm}$.

Pre-operative intra-ocular haemorrhage and uveal prolapse also show a proportionate increase with increase in size of foreign body. 
TABLE III

SIZE OF FOREIGN BODY (89 CASES)

\begin{tabular}{|c|c|c|c|c|c|c|c|c|c|c|c|}
\hline \multirow{2}{*}{$\begin{array}{c}\text { Size } \\
\text { (c.mm.) }\end{array}$} & \multirow{2}{*}{$\begin{array}{l}\text { No. of } \\
\text { Cases }\end{array}$} & \multicolumn{2}{|c|}{ Excised } & \multirow{2}{*}{$\begin{array}{l}\text { Pre-operative } \\
\text { Intra-ocular } \\
\text { Haemorrhage }\end{array}$} & \multicolumn{2}{|c|}{$\begin{array}{c}\text { Pre-operative } \\
\text { Cataract }\end{array}$} & \multicolumn{2}{|c|}{$\begin{array}{c}\text { Post-operative } \\
\text { Cataract }\end{array}$} & \multirow{2}{*}{$\begin{array}{c}\text { Prolapse } \\
\text { of } \\
\text { Uvea }\end{array}$} & \multicolumn{2}{|c|}{ Side } \\
\hline & & No. & $\%$ & & No. & $\%$ & No. & $\%$ & & Left & Right \\
\hline \multicolumn{12}{|l|}{ Less } \\
\hline than 1 & 21 & 1 & 5 & Nil & 10 & 48 & 10 & 48 & $\mathrm{Nil}$ & 7 & 14 \\
\hline $1-2$ & 14 & 2 & 14 & 1 & 8 & 57 & 8 & 57 & $\mathrm{Nil}$ & 5 & 9 \\
\hline $2-4$ & 21 & 1 & 5 & 3 & 7 & 33 & 9 & 43 & 1 & 9 & 12 \\
\hline $4-16$ & 19 & 6 & 32 & 9 & 8 & 42 & 9 & 48 & 6 & 11 & 8 \\
\hline \multicolumn{12}{|l|}{ More } \\
\hline than 16 & 14 & 4 & 28 & 8 & 4 & 28 & 7 & 50 & 4 & 12 & 2 \\
\hline Total & 89 & 14 & 15 & 21 & 37 & - & 43 & - & 11 & 44 & 45 \\
\hline
\end{tabular}

Side.-Perhaps the most unexpected finding is the side involved, which shows a preponderance of $2: 1$ in the right eye for small foreign bodies and of $6: 1$ in the left eye for large ones. There is a gradual swing from right to left preponderance as the foreign bodies increase in size and it is difficult to believe that this is a chance finding. The explanation for the side injured is likely to be found in:

(1) Type of work.

(2) Position of head. One or other eye will be closer to the source of the foreign body and thus more likely to be injured; while the other, farther away, is also protected in part by the nose.

(3) Preponderance of right-handedness and right master-eye, which determines alignment of tools and position of hands, and may result in screening one eye fairly effectively from injury.

Most of the previous series studied show a preponderance of left over right. Goulden (1908) found 67 left and 49 right. . He explains this:

by the fact that the majority of patients are right-handed and the chisel and hammer, from which the majority of intra-ocular foreign bodies come, are used so that the left eye is nearer the area of danger, and also that the nose must be a protection to the right eye.

Sellas (1949) offers a similar explanation. Other figures are given by Sweet (1914) 522 left, 452 right; Gray Clegg (1910), 76 left, 54 right; and Duggan (1933) 146 left, 124 right. These are all civilian series and no bilateral injuries occurred. The causes of injury in military series being different, it is to be expected that both eyes will be equally involved, but Stallard (1944) found 41 right, 34 left, and 30 both; and in a second series (Stallard, 1947) 35 right, 27 left, and 10 both. Bellows (1947), on the other hand, found 32 left, 29 right, and 2 both; he explains that bilateral injuries were fewer because such casualties were for the most part "sent to other installations".

It seems then that, apart from the military series, there is a slight preponderance of lefteye involvement. This statement is further supported by Sellas' large series, which comprised 233 left and 181 right; the present series with 285 left and 270 right shows no undue preponderance.

Goulden and Sellas are the only authors who offer an explanation for this preponderance, and from certain other findings in the present series it seems doubtful whether their explanation is correct. We have already seen that the right eye preponderates for small foreign bodies and the left eye for large ones. The question therefore arises; what is the usual size of fragment occurring in the common accident when hammering and chiselling? This forms the greatest single type of injury in the present series $(30 \cdot 4$ per cent. of the total), 
other injuries occurring while the hand hammer is being used forming an additional 42.5 per cent. Thus, in the total number of cases where the history has been recorded in sufficient detail for the type of injury to be known, 214 (73 per cent.) were injured by a hand hammer accident. The causes have already been discussed.

Type of Injury.-Where the size of foreign body is known as well as the type of injury, it is found that the size has been measured in fourteen known hammer and chisel injuries: the smallest was less than $0.25 \mathrm{c.mm}$., and the largest $9 \mathrm{c.mm}$. (average $2 \mathrm{c.mm}$.). The size is also known in 23 other hand-hammer injuries: the smallest was $0.25 \mathrm{c} . \mathrm{mm}$., and the largest $72 \mathrm{c.mm}$. (average $7.6 \mathrm{c} . \mathrm{mm}$.). In machine-tool accidents the size is known in six cases: the smallest was $0.56 \mathrm{c.mm}$., and the largest $162 \mathrm{c.mm}$. (average $58 \cdot 2 \mathrm{c.mm}$.).

In the whole series the largest foreign body is $304 \mathrm{c.mm}$. and the smallest less than 0.25 c.mm.

It would therefore seem by correlating these figures that the hammer and chisel accident is more likely to affect the right eye in the proportion of $2: 1$.

These findings throw doubt on the accuracy of Goulden's suggestion. The number of cases on which these findings are based is unfortunately rather small and this point will need further investigation before it can be considered as proved.

When the size and position of foreign body are considered it appears that those of less than $1 \mathrm{c} . \mathrm{mm}$. are found proportionately more frequently in the anterior segment, and that those of over $4 \mathrm{c} . \mathrm{mm}$. are more likely to penetrate into the vitreous. This supports the findings of Morax (1917) reported above.

When the final results are correlated with the size of the foreign body, the prognosis for both the excision rate and for final vision deteriorates as the size increases. However, if pre-operative and post-operative states are compared, an increasing proportion of better results occurs as the foreign body increases in size up to $4 \mathrm{c} . \mathrm{mm}$.- -above this the post-operative visual results are much worse.

This may be explained by the nature of the operation itself, in that complications occur with surgery quite apart from the presence of a foreign body. The smallest foreign bodies are less likely to have produced a complication at the time of injury, so that about three-quarters of these cases have a visual acuity better than $6 / 18$ (whereas with the largest foreign bodies three-quarters of the cases have less than $6 / 60$ ). Thus at operation it is easier to produce some deterioration of vision when the foreign body is very small.

It is not until the foreign body exceeds $4 \mathrm{c.mm}$. that with the increase in the excision rate a higher proportion of cases become worse. Similarly, as most of those eyes containing a foreign body over $16 \mathrm{c} . \mathrm{mm}$. in size have pre-operative vision less than $6 / 60$, those eyes which are retained after removal of the foreign body are more likely to show an improvement in vision.

Position of Foreign Body and its Relation to Prognosis.-It has already been seen that, with an increase in excision rate relating to any complication, the visual acuity in the retained eyes also shows a deterioration. Consideration in this section will therefore be limited to the excision rate, since the number of cases involved is rather small and final acuity is subject to chance errors on this account.

The present series shows no excision in a miscellaneous group of small incidence in the posterior chamber (two cases) and a sub-retinal foreign body (one case). In other situations the results are as set out on p. 72 . 


\begin{tabular}{|c|c|c|c|}
\hline \multirow{2}{*}{ Site } & \multirow{2}{*}{ No. of Cases } & \multicolumn{2}{|c|}{ Excision } \\
\hline & & No. & per cent. \\
\hline $\begin{array}{l}\text { Anterior chamber } \\
\text { Cornea } \\
\text { Iris } \\
\text { Lens } \\
\text { Sclera } \\
\text { Vitreous } \\
\text { Retina } \\
\text { Choroid } \\
\text { Ciliary body } \\
\text { Optic Nerve } \\
\text { Transfixing eye }\end{array}$ & $\begin{array}{r}60 \\
23 \\
31 \\
49 \\
24 \\
176 \\
10 \\
5 \\
21 \\
5 \\
2\end{array}$ & $\begin{array}{r}1 \\
1 \\
2 \\
8 \\
4 \\
33 \\
2 \\
1 \\
6 \\
2 \\
2\end{array}$ & $\begin{array}{l}1 \cdot 7 \\
4 \\
6 \cdot 6 \\
16 \\
17 \\
19 \\
20 \\
20 \\
29 \\
40 \\
100\end{array}$ \\
\hline
\end{tabular}

In 148 cases with 49 excisions the site of foreign body is not known because localization charts have been mislaid.

This and previous series show that vitreous foreign bodies were present in most of the cases excised, because of the frequency with which foreign bodies are found in the vitreous. The worst prognosis is that for those cases where the foreign body is lodged in the uveal tract, excluding the iris (from which the removal of foreign bodies is technically easier). The anterior seginent foreign bodies can be seen to have the best prognosis. In the present series the excision rate appears to increase as the penetration of the foreign body becomes greater, with the exception of those impacted in the choroid or ciliary body. At the same time, neither the excision rate, nor, as we see in another section, the visual results support the extreme statement of Würdemann (1932) that:

the results of removal (from the posterior segment) are certainly not so good, for it may safely be said that if the ultimate statistics of cases in which the foreign bodies have been removed from the posterior segment by magnet or otherwise could be obtained, far more than one half would show blindness from irido-cyclitis, atrophy, detached retina, etc., and in a large proportion enucleation had to be done.

\section{VisuAL Results}

The final visual results of some previous series are set out in Table IV. Only those in which sufficient detail is recorded are included; in some cases the figures are a direct quotation, in others they have been worked out from the details given.

TABLE IV

RESULTS GROUPED AS IN PRESENT SERIES

\begin{tabular}{|c|c|c|c|c|c|c|c|c|c|c|c|}
\hline \multicolumn{2}{|c|}{ Author } & Goulden & Allport & Duggan & Sherman & $\begin{array}{l}\text { Trevor- } \\
\text { Roper }\end{array}$ & $\begin{array}{c}\text { Desvignes } \\
\text { and } \\
\left.\text { Boudon ( }{ }^{1}\right)\end{array}$ & $\underset{\left({ }^{2}\right)}{\text { McBride }}$ & $\begin{array}{l}\text { Roper- } \\
\text { Hall ( }{ }^{(3)}\end{array}$ & $\begin{array}{c}\text { Sellas } \\
\left({ }^{4}\right)\end{array}$ & $\begin{array}{c}\text { Present } \\
\text { Series }\end{array}$ \\
\hline \multicolumn{2}{|c|}{ Date } & 1908 & 1925 & 1933 & 1939 & 1944 & 1947 & 1949 & 1952 & 1949 & 1953 \\
\hline \multirow{2}{*}{$\begin{array}{l}\mathbf{v} \\
\mathbf{i} \\
\mathbf{s} \\
\mathbf{u} \\
\mathbf{a} \\
\mathbf{1}\end{array}$} & $\begin{array}{c}\text { Eye } \\
\text { Excised }\end{array}$ & 35 & 33 & 25 & \multirow{2}{*}{40} & 18 & $20 \cdot 8$ & 20 & 17 & $13 \cdot 28$ & 20 \\
\hline & $\begin{array}{l}\text { Less } \\
\text { than } \\
6 / 60\end{array}$ & 15 & 25 & 30 & & 32 & $42 \cdot 6$ & 26 & 21 & 40 & 22 \\
\hline \multirow{3}{*}{$\begin{array}{c}\mathbf{R} \\
\mathbf{e} \\
\mathbf{s} \\
\mathbf{u} \\
\mathbf{1} \\
\mathbf{t} \\
\mathbf{s}\end{array}$} & $6 / 60-$ & 16 & 6 & $11^{*}$ & 8 & 9 & $15 \cdot 6$ & $4^{*}$ & 8 & 7 & 9 \\
\hline & $6 / 18-$ & 18 & 14 & $18^{*}$ & 26 & 25 & $11 \cdot 4$ & $12^{*}$ & 26 & 20 & $24 \cdot 5$ \\
\hline & $6 / 6+$ & 16 & 22 & 16 & 26 & 16 & $9 \cdot 3$ & 38 & 28 & 20 & 24.5 \\
\hline \multicolumn{2}{|c|}{$\begin{array}{l}\text { Route } \\
\text { Favoured }\end{array}$} & Anterior & Posterior & Anterior & Posterior & Anterior & - & Posterior & - & - & - \\
\hline
\end{tabular}

*Approximate estimate on basis of other series. Figures not given by Author. 
Certain series cannot fairly be used in any comparison as they refer to military cases, in which, apart from the points of difference already mentioned, the follow-up period and final visual results are uncertain.

In some other series the results are divided into groups of good, moderate, and bad, no detailed visual acuity being given.

Finally, there is no internationally standard method of recording visual acuity, so that it has not always been feasible to translate the description given into the Snellen 6/60-6/6 series in use in Great Britain; but this has been done as accurately as possible where the data permitted. Comparison can be made between the present series and all those represented in Table IV except that of Sellas, whose published results appear with a separate heading for aphakic cases. In the remainder of the series reviewed, aphakic cases are combined with the other results. Approximate estimations of the percentages of final acuity in Sellas' series are given in Table IV after excluding all aphakic cases; the excision rate is his own figure. The series of Stieren (1932) has been omitted because the results appear misleading.

Owing to individual inaccuracies which can easily occur in vision testing, especially in the urgency of this type of case, it was felt wise to group the cases into four grades of vision. Those with no useful vision (less than 6/60), those with some useful vision (6/60-6/24), those with vision sufficient to carry out most tasks and perhaps allow binocular vision (6/18-6/9), and those with normal visual acuity $(6 / 6+)$.

It is very noticeable that in previous series favouring the posterior route there is a higher percentage of visual results $6 / 6+$ than in series favouring the anterior route. Table IV shows the route preferred by each author, and all three anterior route series show 16 per cent. of cases reaching $6 / 6+$, whereas the posterior route series show improvement with the passage of time up to an average of 29 per cent. The present series with its mixed affinities gives a figure of $23 \cdot 5$ per cent.

The outstanding differences from the average occur in the column 6/6 and better. The very low figure of Desvignes and Boudon (1947) is difficult to explain, but the fact that 32 per cent. were due to war injuries may account for it. A similar low figure is found in the military series of Bellows (1947).

The high figure of 38 per cent. (McBride, 1949) is also outstanding; these cases are stated by him to have recovered " normal vision ", and in view of the low figure in the preceding column it seems possible that " normal vision" includes 6/9. It should also be noted that this is the smallest of the series reviewed.

Otherwise Table IV shows many similarities, and it seems that most of the civilian series are much the same as regards type of injury, magneticity, and final visual results.

Length of Follow-Up before Final Assessment. - A number of authors think that results are given in many series without sufficient follow-up.

Thus Goulden (1908) limited his series, with few exceptions, to patients who were re-examined at least one year after the extraction or attempted extraction of the 
foreign body. His total number of cases in which the eye was retained was thus reduced from 80 to 42 , and this appears to have led to much greater inaccuracy than if the remaining 38 cases had been included.

The unanswered question is: What was the reason for failure to re-attend? Possibly the patient's vision was so nearly normal that he felt it unnecessary to continue attending hospital, but on the other hand he might have decided to go elsewhere. The latter seems the less likely, as Goulden's figures show that many of the cases in which follow-up was not possible had good vision when last seen; also, if any complication occurs, a patient is more likely to return to the hospital where his condition is known. A third possibility is that, having returned to work and completed compensation proceedings within about 6 months, the patient considered the matter closed. Goulden's own suggestion, which may have applied in 1908, certainly does not do so today, though it is just as difficult to persuade patients to re-attend now as it was apparently then. Goulden says that non-attendance was:

of course, due to the fact that the majority of accidents of this nature occur in patients of the labouring class, who are constantly moving about the country.

Each of these reasons may play a part, but most of the patients who failed to re-attend probably belonged to the first group of good results.

Brownlie (1915), declaring the need for long term follow-up, quotes Rogers (no reference) as saying that care must be taken in accepting statistics of favourable immediate results.

Kiehle (1932) criticizes the idea, which appears to have been prevalent at the time, that a foreign body removed is an eye saved. After a survey of the literature he concludes that the longer a case is followed up the greater is the diminution of vision which is observed.

This stimulated Cridland in England and Duggan in America to consider this problem of aftermath.

Duggan.(1933), considering nine cases seen at regular intervals after removal of the foreign body, found that in all except one (where a second trauma was received) the visual acuity had become stabilized within a year, and that seven showed a progressive improvement during the follow-up period.

Cridland (1933) appears to agree with Kiehle, whom he quotes freely. In an extensive search of the literature for late results, he was able to find 77 reports of cases in which eyes were re-examined over 5 years after penetration by a magnetic foreign body. He also quotes Stieren (1932) whose figures are presented in an ambiguous manner. Although "final" vision was given for all cases, the only figure for excisions was 15 per cent. immediately excised. Since there must have been some late excisions, it can hardly be true that follow-up was between 1 and 25 years between operation and final examination, as is implied by Stieren and accepted by Cridland and subsequent authors, but criticized by Duggan. Cridland pointed out that nineteen of the cases referred to in his paper were ones of impacted foreign body (of which the magnetism must be in doubt, in spite of Cridland's statement that all his cases were magnetic), and that 69 were cases of successful removal of foreign body from the posterior segment. He compared the results in these two groups and found them similar. He did not advocate leaving a foreign body in the globe, but considered:

that excessive surgical intervention is contraindicated when these aftermath results are borne in mind. 
These are sweeping conclusions to draw from a small series of cases, and the two groups are not comparable because the site of foreign body is different, nor do they represent a cross-section of all cases of intra-ocular foreign body.

An attempt has been made in the present series to compare the visual results according to the length of follow-up after removal or attempted removal of the foreign body. All excisions are excluded; their inclusion would not help to clarify the matter, as most of them were carried out within the first 3 months. The results of this analysis are set out in Table V. With increasing length of follow-up there is no marked change in the proportion of cases in each group except where the follow-up period is less than 3 months. Thus in the 3-6 months group, 58 per cent. of the 63 cases achieve 6/18 or better, and in the over 2 years group 59.7 per cent. of the 72 cases achieve this degree of acuity. This indicates that Kiehle's statement that "the longer the period of time elapsing, the greater seems to be the diminution of vision" is not correct.

TABLE V

VISUAL RESULTS IN PRESENT SERIES AT DIFFERENT PERIODS OF FOLLOW-UP

\begin{tabular}{|c|c|c|c|c|c|c|c|c|c|}
\hline \multirow{2}{*}{ Follow-up Period } & \multicolumn{2}{|c|}{ Less than $6 / 60$} & \multicolumn{2}{|c|}{$6 / 60-6 / 24$} & \multicolumn{2}{|c|}{$6 / 18-6 / 9$} & \multicolumn{2}{|c|}{$6 / 6+$} & \multirow{2}{*}{ Total } \\
\hline & No. & $\%$ & No. & $\%$ & No. & $\%$ & No. & $\%$ & \\
\hline $\begin{array}{l}\text { More than } 2 \text { yrs } \\
1-2 \text { yrs } \\
6 \text { mths-1 yr } \\
3-6 \text { mths } \\
\text { Less than } 3 \text { mths }\end{array}$ & $\begin{array}{l}27 \\
18 \\
23 \\
17 \\
24\end{array}$ & $\begin{array}{l}34 \cdot 8 \\
39 \\
40 \\
27 \\
16 \cdot 5\end{array}$ & $\begin{array}{r}\cdot 4 \\
3 \\
6 \\
10 \\
21\end{array}$ & $\begin{array}{l}5 \cdot 8 \\
6 \cdot 5 \\
9 \cdot 5 \\
17 \\
14 \cdot 5\end{array}$ & $\begin{array}{l}15 \\
16 \\
12 \\
18 \\
55\end{array}$ & $\begin{array}{l}22 \\
35 \\
19 \\
28 \\
38\end{array}$ & $\begin{array}{l}26 \\
10 \\
20 \\
18 \\
45\end{array}$ & $\begin{array}{l}37 \cdot 7 \\
19 \cdot 52 \\
32 \\
28 \\
31\end{array}$ & $\begin{array}{r}72 \\
47 \\
61 \\
63 \\
145\end{array}$ \\
\hline $\begin{array}{l}\text { Overall per cent. } \\
\text { (approx.) }\end{array}$ & & 30 & & 10 & & 30 & & 30 & 389 \\
\hline
\end{tabular}

While rather better results are seen in the cases with less than 3 months' follow-up, it must be remembered that in some of them the patient is not aware that anything serious has happened to his eye. He knows that the foreign body is out and that he sees well and has had no complication, and so he goes back to work; the case is reported, but the patient "forgets" to attend hospital since he considers it a waste of everyone's time.

It may seem that this point is being over-emphasized by the writer, but, in view of the repetition of conclusions based on the long follow-up of a selected group of cases with relatively bad prognosis, it is felt that it cannot be emphasized too much.

In the present series, when the records of the two extreme follow-up periods are analysed by site of foreign body, it is found that more cases of anterior segment foreign bodies are followed-up for less than 3 months, and that more cases of vitreous foreign bodies have the longest follow-up periods. This difference does not appear conclusive. Nevertheless we find that while cataract was present post-operatively in 32 per cent. of cases in the shortest follow-up period, it was present in 48 per cent. of those in the longest. Retinal detachment occurred in 3 per cent. of the shortest and in 17 per cent. 
of the longest. In other words, patients with complications are more likely to continue attendance.

Ideally, a longer follow-up period is desirable, but there is no satisfactory evidence to show that deterioration of vision is to be expected over such a period. Certain inaccuracies are likely to occur in recording end-results with only short periods of follow-up, but far greater inaccuracies will occur if series are reduced to include only those with a long follow-up period.

A definite answer to the problem of aftermath can only be given by repeated examinations of a representative group of patients, but this is almost impossible to arrange. In the individual cases reported, rather more show an improvement of vision with the passage of time than show a deterioration. When cases are grouped according to length of follow-up, little significant difference is noticed except in those followed for less than 3 months. It is therefore suggested that series should remain complete, but that the length of follow-up before assessing the end-result should be recorded, to check inaccurate comparison.

Effect of Delay in Removal of the Foreign Body.-There is a great deal of emphasis in the literature on the need for rapid removal of the foreign body.

Brownlie (1915), Shoemaker (1919), Würdemann (1932), and Sherman (1939) all hold the view that early extraction is essential even though the foreign body has not been exactly located.

This is the crucial point. Should one wait for accurate localization or must the foreign body be extracted at once? Trevor-Roper (1944), reviewing the delay period in his series, found that it did not seem materially to prejudice the issue, although in two cases siderosis was evident which could have been averted.

Gundersen (1947) reviewed this question more fully; he questioned the rate at which foreign bodies became firmly embedded, an suggested that once preliminary clotting was over the further fixing of the foreign body would be slow. He also mentioned factors of infection, which I believe to be very important to this problem, justifying the advice of the earlier authors for speed, but expressing doubts about its validity to-day. What was once a common complication if removal was unduly delayed has now become a comparative rarity. Gundersen concluded this section of his article with a plea that emphasis be changed from speed of extraction to accuracy of localization.

It is true that if the anterior route is chosen the accuracy of localization is less important when the lens is damaged, but without accurate knowledge of the position of the foreign body the direction of pull cannot be planned. I, therefore, believe that, where the lens is undamaged, the foreign body posteriorly placed, and the anterior route chosen, accurate localization is the first necessity.

Clearly, if there is a gaping wound or uveal prolapse, the case must be treated as one of urgency, and surgical toilet carried out at once. Localization is then of little or no importance and delay is not justified. Gundersen's views are well expressed but are not supported by examples.

In Fig. 2 the cases of successful removal in the present series have been arranged according to the length of time between injury and removal of the foreign body. Cases with retained foreign bodies have been omitted because the increased proportion of non-magnetic foreign bodies would tend to 
obscure the result, and in some cases no attempt at removal was made.

Naturally all foreign bodies removed on the first day were removed at the first attempt, so we have a 100 per cent. figure. On the other hand, cases in which the foreign body was removed on the second day include many of the first day's failures, which may account for the relatively low percentage of successful removals at the first attempt (84.6 per cent.) among them. It is therefore suggested that the figures for the first and second days should be considered

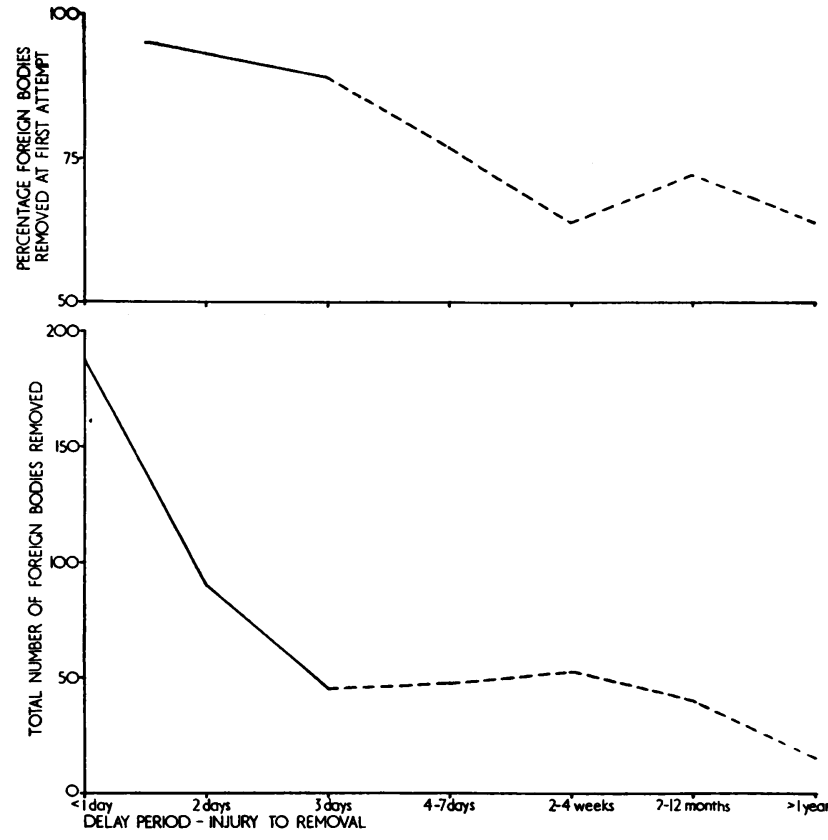

FIG. 2.-Effect of delay in removal on fixation of foreign bodies, showing percentage removed at first attempt and total removed.

together, which gives 95 per cent. removed at the first attempt. In the whole series, 428 foreign bodies were removed at the first attempt out of a total 495 (86.6 per cent.), but within the first 3 days this figure was bettered. These percentages show the progressive increase in difficulty in removing a foreign body as time passes, but this difficulty does not show itself markedly in a few hours or even in a few days, and Gundersen's opinion that accurate localization should not be neglected for the sake of speed is justified. In spite of this there is still a large body of opinion which emphasizes the need for urgent removal. Anderson (1951) reported that the foreign body became insulated if it were allowed to remain for a period of time; he thought that it should be removed, if possible, within 24 hours, and this appeared to be the general opinion at the meeting of the Ophthalmological Society of the United Kingdom at which he was speaking.

It is my view that the foreign body should be removed as early as possible but not at the expense of full investigation and localization. In making a decision the fixation of the foreign body is less important than the final visual result.

Table VI (overleaf) shows the visual results when the cases are grouped according to the period between injury and removal. This Table agrees with Trevor-Roper's series in that the excision rate is highest in cases in which the foreign body was removed on the first day, and second in those in which 
it was removed on the second day. It is also striking that the lowest figure comes on the third day. After this the excision rate becomes more stable and shows no increase with further delay.

TABLE VI

VISUAL RESULTS AFTER DELAY IN REMOVAL OF FOREIGN BODIES 479 Cases (excluding retained foreign bodies and those with unknown time lag)

\begin{tabular}{|c|c|c|c|c|c|c|c|c|c|c|c|}
\hline \multirow{3}{*}{ Delay } & \multicolumn{11}{|c|}{ Visual Results } \\
\hline & \multicolumn{2}{|c|}{ Excised } & \multicolumn{2}{|c|}{$\begin{array}{c}\text { Less than } \\
6 / 60\end{array}$} & \multicolumn{2}{|c|}{$6 / 60-6 / 24$} & \multicolumn{2}{|c|}{$6 / 18-6 / 9$} & \multicolumn{2}{|c|}{$6 / 6+$} & \multirow{2}{*}{$\begin{array}{l}\text { Un- } \\
\text { known } \\
\text { End- } \\
\text { result" }\end{array}$} \\
\hline & No. & $\%$ & No. & $\%$ & No. & $\%$ & No. & $\%$ & No. & $\%$ & \\
\hline $\begin{array}{l}\text { Up to } 1 \text { day } \\
\text { 2nd day } \\
\text { 3rd day } \\
\text { 4th-7th day } \\
\text { 2nd-4th wk } \\
\text { 2nd-12th mth } \\
\text { More than } 1 \text { yr }\end{array}$ & $\begin{array}{r}54 \\
13 \\
1 \\
6 \\
5 \\
2 \\
1\end{array}$ & $\begin{array}{c}31 \\
16 \\
2 \\
13 \cdot 3 \\
10 \cdot 5 \\
6 \\
7\end{array}$ & $\begin{array}{r}31 \\
17 \\
10 \\
7 \\
16 \\
10 \\
6\end{array}$ & $\begin{array}{l}18 \\
21 \\
24 \\
15 \cdot 5 \\
34 \\
30 \cdot 3 \\
43\end{array}$ & $\begin{array}{l}7 \\
5 \\
7 \\
4 \\
6 \\
5 \\
1\end{array}$ & $\begin{array}{r}4 \\
6 \\
17 \\
9 \\
13 \\
15 \\
7\end{array}$ & $\begin{array}{r}36 \\
17 \\
12 \\
14 \\
13 \\
11 \\
4\end{array}$ & $\begin{array}{l}21 \\
21 \\
28 \cdot 5 \\
31 \cdot 1 \\
27 \cdot 5 \\
33 \cdot 3 \\
29\end{array}$ & $\begin{array}{r}45 \\
29 \\
12 \\
14 \\
7 \\
5 \\
2\end{array}$ & $\begin{array}{l}26 \\
36 \\
28 \cdot 5 \\
31 \cdot 1 \\
15 \\
15 \\
14\end{array}$ & $\begin{array}{r}14 \\
10 \\
4 \\
3 \\
6 \\
6 \\
1\end{array}$ \\
\hline
\end{tabular}

*These are unlikely to include any excisions.

Approximate percentages appearing in this Table are given after excluding the unknowns.

It will also be noticed that with a longer delay there is a progressive increase in the proportion of cases with vision less than 6/60 and a decrease in those achieving $6 / 6$ or better. The intermediate columns show little variation. As we are dealing only with magnetic foreign bodies in this Table, it seems possible that this deterioration in results is due partly to subclinical siderosis.

Desvignes and Boudon (1947) also found that cases in which the foreign body was removed between 24 hours and 20 days after injury (average 6 days)

TABLE VII

COMPARISON OF VISUAL ACUITY AND COMPLICATIONS ON FIRST ATTENDANCE BETWEEN CASES WITH DELAY OF LESS THAN 24 HRS AND THE SERIES AS A WHOLE

\begin{tabular}{|c|c|c|c|c|c|}
\hline \multicolumn{2}{|c|}{ Visual Result } & \multicolumn{2}{|c|}{$\begin{array}{l}\text { Less than } 24 \text { hrs from } \\
\text { Injury to Removal (187) }\end{array}$} & \multicolumn{2}{|c|}{ Whole Series (555) } \\
\hline & & No. & $\%$ & No. & $\%$ \\
\hline $\begin{array}{l}\text { Original Visual } \\
\text { Acuity }\end{array}$ & $\begin{array}{l}\text { Less than } 6 / 60 \\
6 / 60-6 / 24 \\
6 / 18-6 / 9 \\
6 / 6+ \\
\text { Not known }\end{array}$ & $\begin{array}{r}73 \\
22 \\
61 \\
27 \\
4\end{array}$ & $\begin{array}{r}39 \\
12 \\
32 \\
15 \\
2\end{array}$ & $\begin{array}{r}189 \\
97 \\
196 \\
62 \\
12\end{array}$ & $\begin{array}{r}34 \\
18 \\
35 \\
11 \\
2\end{array}$ \\
\hline \multicolumn{2}{|c|}{$\begin{array}{l}\text { Uveal prolapse } \\
\text { Pre-operative cataract } \\
\text { Disorganization } \\
\text { Pre-operative intra-ocular haemorrhage }\end{array}$} & $\begin{array}{l}33 \\
61 \\
12 \\
55\end{array}$ & $\begin{array}{l}17 \cdot 6 \\
32 \cdot 6 \\
6 \cdot 4^{*} \\
29 \cdot 4\end{array}$ & $\begin{array}{r}46 \\
219 \\
15 \\
109\end{array}$ & $\begin{array}{r}8 \cdot 3 \\
39 \cdot 5 \\
2 \cdot 7 \\
19 \cdot 6\end{array}$ \\
\hline
\end{tabular}

\footnotetext{
*Eleven cases also had uveal prolapse
} 
gave better results than those in which it was removed within 24 hours. They mention their difficulty in finding factors which might even partly explain this paradox. They point out especially that the proportion of anterior and posterior segment foreign bodies is the same in the two groups. They submit as a possible explanation that the patients with the more severe damage, caused by the largest foreign bodies, were directed to the hospital without delay (cf. Trevor-Roper), but these factors are incompletely recorded in their cases and they admit that their suggestion is only a hypothesis.

The explanation offered by Trevor-Roper and by Desvignes and Boudon is a logical one, and yet if an attempt is made to assess the relative severity of damage to the eyes with foreign bodies removed within the first 24 hours on the basis of original visual acuity (Table VII) there is no significant difference between these cases and the whole series. Nor is the proportion of cases with cataract suggestive of increased damage, but rather the opposite.

However, there is a markedly higher proportion of first day cases with uveal prolapse, intra-ocular haemorrhage, and disorganization. These complications are all related to an increase in the excision rate.

Fig. 3 shows that Desvignes and Boudon were correct in their suggestion that the larger foreign bodies are found in those patients attending for their removal on the first day. There are proportionately fewer cases on the first day with foreign bodies less than $4 \mathrm{c} . \mathrm{mm}$. and more with foreign bodies larger than this.

.There is therefore little doubt that the paradox of the foreign bodies removed within 24 hours is due to the fact that the most severely damaged eyes are seen within this period.

However, in view of the extremely low figure for excisions in cases of foreign bodies removed on the third day, it is tempting to suggest as a possible additional factor that the eye subsequently settles better if given time to recover from the first insult of the accident, before being exposed to the second insult of the operation.

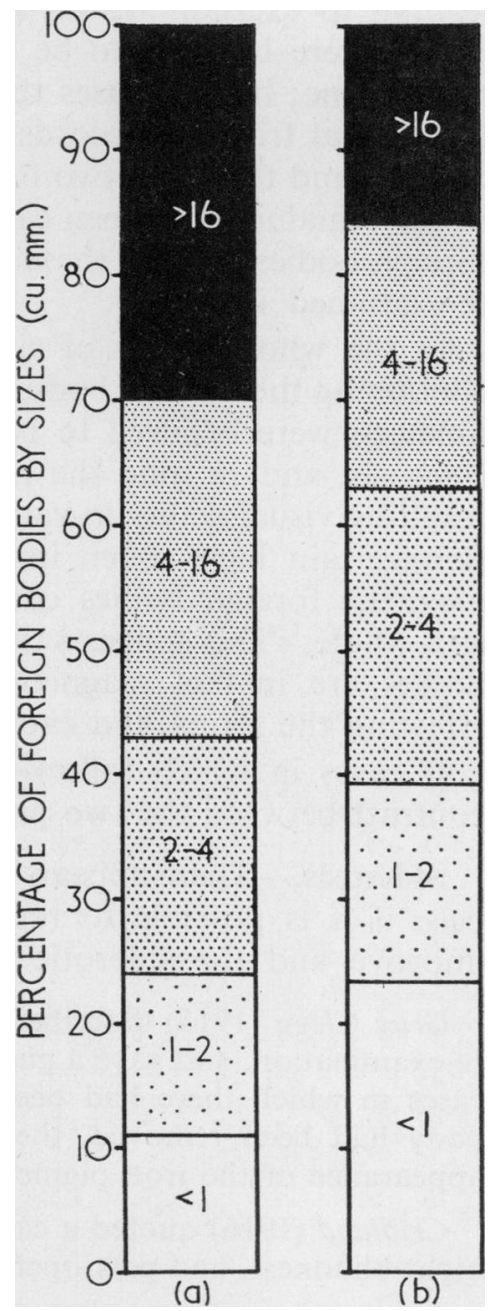

FIG. 3. - Relative proportions of foreign bodies of different sizes. (a) removed within 24 hrs.

(b) removed after any period. 
Retained Foreign Bodies. -429 foreign bodies out of the total of 555 (just over 77 per cent.) were removed at the first attempt, and 66 at subsequent attempts, and sixty were retained. In those cases where further attempts at removal were deemed justifiable, the second attempt was successful in 58 per cent., the third in 46 per cent., and the fourth or later in 66.6 per cent. In all, 89 per cent. were removed by magnet or with forceps.

In four cases in which no attempt was made to remove the foreign body, there were complications which necessitated primary excision. In 15 of 29 cases in which only one attempt was made, there were complications leading to excision within a few days of injury. In ten cases the foreign bodies were believed to be non-magnetic and it was thought best to leave them alone; in four cases the reason for deciding against a further attempt is not clear from the records; two of these have been followed for more than 2 years, and the other two for over one year. No siderosis developed in any of the remaining fourteen cases; two patients were believed to have had steel foreign bodies; one of these had been present since 1942 and the patient was re-examined in 1951.

In the whole group of sixty cases with retained foreign bodies, 26 eyes containing the foreign body were subsequently excised. Of the remaining 34 , nineteen were believed to have non-magnetic foreign bodies, six developed siderosis, and in nine the magnetism is uncertain. A comparison of the resulting visual acuity in various cases shows that those in which magnetism is uncertain have much impairment, while the results in those with nonmagnetic foreign bodies compare very favourably with those in the series as a whole. This suggests that in a number of the uncertain cases the foreign bodies are in fact magnetic, and that sub-clinical siderosis has occurred affecting the retina and causing poor visual acuity.

If cases in which follow-up was less than 12 months are excluded, this contrast between the two groups becomes even more marked.

Siderosis. - There appears to be a widely held opinion that, in cases of siderosis, if it is possible to remove the foreign body successfully, vision may improve and the siderotic pigment gradually disperse.

Gray Clegg (1915) described seven cases which he had been unable to trace for re-examination, and gave a guarded prognosis, but in 1926 he said that he had had cases in which there had been definite siderosis and in which, once the foreign body had been removed, the eye recovered with good vision and gradual disappearance of the iron pigmentation. Unfortunately he gave no details.

Cridland (1916) quoted a case in which visual acuity pre-operative was $6 / 6$ with night-blindness, and post-operative 6/5 (partly) with a full field to white and red.

Barkan and Barkan (1927) gave information on eight cases in their series, saying that seven foreign bodies were extracted successfully and that in these cases vision was maintained or subsequently improved by extraction of cataract, but they contradicted themselves in the same paragraph by giving details of one of these 
cases in which pre-operative and immediate post-operative vision was $0 \cdot 8$. Cataract developed one year later and was extracted, but vision was only perception of light " in spite of black pupil and clear media". They therefore concluded that in this case siderosis of the retina had continued after extraction of the foreign body.

Davidson (1933), reporting fifteen cases, offered no evidence that vision can be expected to improve with time after siderosis has been present and the foreign body successfully removed.

Duggan (1933) found in all but one of sixteen cases that the presence of siderosis could be taken to be an indication that degenerative changes had already begun and would progress; thus supporting the contention of Verhoeff (1932) that siderotic degeneration continues notwithstanding the removal of the foreign body.

Sherman (1939) observed siderosis showing no sign of disappearance in seven eyes.

In the present series, there were 25 cases of siderosis ( 4.5 per cent.); the foreign body was successfully removed in fifteen (Table VIII), but in only three of these cases was the vision found to improve; it remained the same in four cases, and became worse in seven, and in the one remaining case there was no record of post-operative visual acuity.

TABLE VIII

SIDEROSIS CASES IN PRESENT SERIES IN WHICH FOREIGN BODY WAS REMOVED

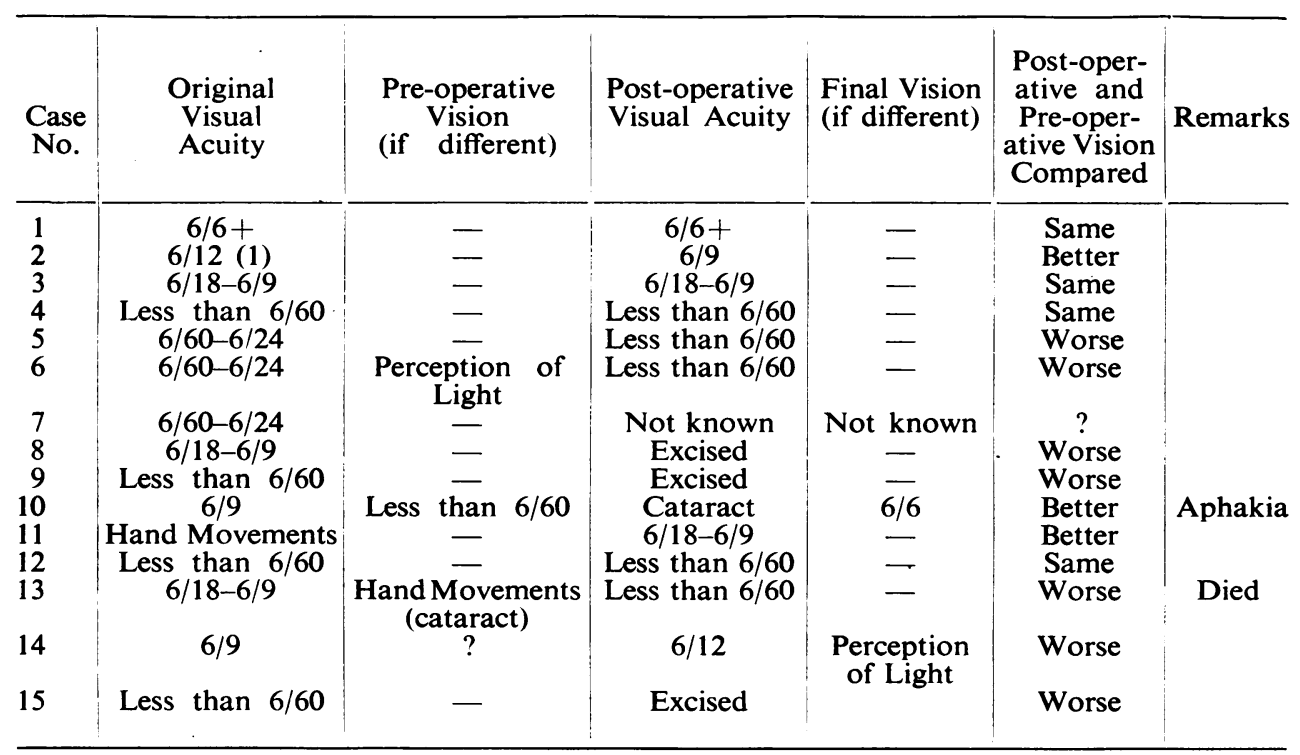

It can therefore be said that neither the literature nor the present series offer any evidence to support the view that an improvement of vision is likely to take place in cases of siderosis after the foreign body is removed, for this occurred in only five out of a total of 27 reported cases. On the other hand, visual improvement is often seen after cataract extraction in siderotic eyes. 


\section{ChOICE OF ANTERIOR OR POSTERIOR ROUTE}

Whether a posteriorly placed foreign body should be removed via the anterior chamber and a corneal section (anterior route) or directly through retina, choroid, and sclera (posterior route) has been a subject of controversy, acrimony, and prejudice since the earliest days of magnet extraction.

Many series of cases have been published in which almost all the foreign bodies have been removed by one or other route (Gulliver, 1942, 1,800 cases, posterior route in six only; Stieren, 1932, posterior route in all vitreous cases), so that a strict comparison is not possible. In the present series there is a more even balance between the routes and a useful comparison can be made.

There is a tendency among authors to argue, from the relative numbers of successful removals of foreign bodies by each route, the risk of inducing cataract by the anterior route and the risk of detachment or intra-ocular haemorrhage by the posterior route. I contend that the only criterion is the final result. In the present series, a comparison of the excision rates and the final visual acuity is made, but it should be borne in mind that an aphakic $6 / 6$ final vision is only potentially useful, in comparison with the retention of an undamaged lens, 6/6 vision, and binocular stereopsis.

In reviewing the literature it should be remembered that with the decline in the rate of incidence of uncontrolled infection the posterior route of removal has produced fewer disasters of the kind described by those who condemn it. Taking the various articles in order of date we see that the arguments change little with the passage of time.

Goulden (1908) strongly advocated the anterior route; he limited his series to 42 cases, in almost all of which an examination was made at least one year after removal, but he also tabulated 38 cases in which the eye was excised (none of which were considered in his main series), and 38 cases in which the follow-up was less than one year. A consideration of these Tables throws doubt on his conclusions. For instance, in his Table of cases coming to excision, we find thirty cases of removal by the anterior route ( 37 per cent. of all anterior removals), and eight cases of removal by the posterior route ( $29 \cdot 5$ per cent. of all posterior removals).

For this and other reasons I feel it would be better if Goulden's 118 cases were considered together. I find then that the figures give a very different picture; of his 118 cases, six had retained foreign bodies, and for two others no final visual acuity was recorded. Of the remaining 110 cases, 67 had foreign bodies removed from the vitreous, 27 by the posterior route and forty by the anterior. A higher proportion of anterior removals achieved $6 / 12$ or better ( $27 \cdot 5$ per cent. compared with $18 \cdot 5$ per cent. posterior removals), but the fact that $18 \cdot 5$ per cent. of the posterior removals did in fact achieve this satisfactory standard is completely hidden by the manner in which Goulden's series is presented. The reader is left with the impression that to use the posterior route is almost certain to lead to disaster, and yet from Goulden's own figures we find that the excision rate is slightly lower in cases where the posterior route has been used, and that the visual results of the whole series show a less gloomy picture.

Stieren (1913) and Sweet (1914) favoured the posterior route for vitreous foreign bodies.

Brownlie (1915) was in favour of the anterior route because he considered that the posterior route inflicted further damage. 
Allport (1925) recorded details of 223 cases, but left the reader to draw his own conclusions from them.

Barkan and Barkan (1927) concluded that the anterior route should be used whenever it was at all possible.

Verhoeff (1932) advocated the anterior route because it involved no scleral incision which might lead to separation of the retina.

Stieren (1932) favoured the posterior route and claimed a wide experience with this type of operation; his article is a strong statement of opinion directly opposed to Verhoeff, but his results are given in an ambiguous manner and are not helpful in comparing the two routes.

Duggan (1933) criticized Stieren's paper and in general advocated the anterior route.

Sherman (1939) reviewed 120 cases in which, I believe, the first comparison was made between the anterior and posterior routes in removing foreign bodies from vitreous and retina with an adequate tabulation of results. He concluded that, though he had formerly used the anterior route for vitreous foreign bodies, during the past 20 years he had been using the posterior route with increasing frequency and found it justified by results.

Gulliver (1942) reported his experiences " among more than 1,800 intra-ocular foreign bodies". His results are so arranged that it is not possible to compare them with others.

Trevor-Roper (1944) reviewed 154 magnet removals at Moorfields Eye Hospital in which the posterior route was used in only four cases.

Desvignes and Boudon (1947) in a comprehensive article seemed to show that the posterior route produced the better final results.

Gundersen (1947) gave a balanced discussion on the route which should be used, but the present series will be found to indicate a different method of selection.

McBride (1949) stated that both routes were used in the fifty cases reported.

These articles show that too often figures have been compared which are not strictly comparable, and that conclusions so reached may be invalid. The present series may prove too small for definite conclusions to be reached on all the relative indications for the two routes, but it is believed that the more important indications are clearly apparent. In the whole of the present series 376 cases were operated upon by the anterior route only, 132 by the posterior route only, and 39 by both routes. No attempt was made to remove the foreign body in four cases and in four the route of removal is not recorded.

Visual Results. - A survey of the 39 cases in which both routes were used in successive attempts at removal show that both failed in nine cases; in one case two foreign bodies were present and one was extracted by each route. In the remaining 29 cases, the posterior route was successful when the anterior route had failed: in sixteen of these the foreign body was in the vitreous, in four in the choroid and retina, in two in the ciliary body, and in one in the sclera; in the remaining seven the localization is not known.

Table IX gives details of the 132 posterior route cases. The foreign body was removed by magnet at the first or subsequent attempt in 122 cases $(92 \cdot 4$ per cent.; 88 per cent. at first attempt) and was retained in ten cases ( 7.6 per cent.). Fifteen eyes (11.4 per cent.) were subsequently excised; three of these were disorganized with large scleral wounds when first seen. Retinal detachment was present postoperatively in twenty cases (15 per cent.) in which it had not been present preoperatively. Intra-ocular haemorrhage was present pre-operatively in 36 cases ( 27 per cent.) and was first seen after operation in 26 cases (19.7 per cent.). The 
TABLE IX

ANALYSIS OF REMOVALS BY ANTERIOR AND POSTERIOR ROUTES

\begin{tabular}{|c|c|c|c|c|}
\hline Route & $\ldots$ & $\ldots$ & Posterior & Anterior \\
\hline \multirow{2}{*}{$\begin{array}{c}\text { Fate of } \\
\text { Foreign Body }\end{array}$} & Removed & $\begin{array}{l}\text { at } 1 \text { st attempt } \\
\text { at } 2 \text { nd attempt } \\
\text { at } 3 \text { rd attempt } \\
\text { at } 3+\text { attempts }\end{array}$ & $\begin{array}{r}116 \\
5 \\
1 \\
0\end{array}$ & $\begin{array}{r}325 \\
11 \\
3 \\
2\end{array}$ \\
\hline & Retained & $\begin{array}{l}\text { after } 1 \text { attempt } \\
\text { after } 2 \text { attempts } \\
\text { after } 3 \text { or more attempts }\end{array}$ & $\begin{array}{l}6 \\
3 \\
1\end{array}$ & $\begin{array}{r}22 \\
11 \\
2\end{array}$ \\
\hline $\begin{array}{l}\text { Pre-operative } \\
\text { Complications }\end{array}$ & \multicolumn{2}{|c|}{$\begin{array}{l}\text { Disorganization } \\
\text { Retinal Detachment } \\
\text { Intra-Ocular Haemorrhage }\end{array}$} & $\begin{array}{r}3 \\
6 \\
36\end{array}$ & $\begin{array}{r}14 \\
5 \\
71\end{array}$ \\
\hline $\begin{array}{l}\text { Site of } \\
\text { Foreign Body }\end{array}$ & \multicolumn{2}{|c|}{$\begin{array}{l}\text { Vitreous } \\
\text { Sclera } \\
\text { Lens } \\
\text { Cornea, Anterior Chamber, or Iris } \\
\text { Other } \\
\text { Not certain }\end{array}$} & $\begin{array}{l}84 \\
13 \\
- \\
14 \\
21\end{array}$ & $\begin{array}{r}69 \\
48 \\
112 \\
32 \\
115\end{array}$ \\
\hline $\begin{array}{l}\text { Final } \\
\text { Visual } \\
\text { Results }\end{array}$ & \multicolumn{2}{|c|}{$\begin{array}{l}\text { Excision } \\
\text { Less than } 6 / 60 \\
6 / 60-6 / 24 \\
6 / 18-6 / 9 \\
6 / 6+ \\
\text { Not known }\end{array}$} & $\left.26\} \begin{array}{l}15 \\
33 \\
12 \\
42\end{array}\right\} \begin{array}{l}68(51 \cdot 5 \%) \\
4\end{array}$ & $\begin{array}{c}83 \\
70 \\
26 \\
85 \\
72\} \\
157(41 \cdot 7 \%) \\
40\end{array}$ \\
\hline \multicolumn{3}{|l|}{ Total } & 132 & 376 \\
\hline
\end{tabular}

final visual results show that 68 cases $(51 \cdot 5$ per cent.) achieved $6 / 18$ or better, and that 42 of these ( 32 per cent.) achieved $6 / 6$ or better.

Table IX also gives details of the 376 anterior route cases. The foreign body was removed at the first or subsequent attempt in 341 cases $(90.7$ per cent. ; 86.4 per cent. at the first attempt), and was retained in 35 cases $(9 \cdot 3$ per cent.). 83 eyes ( 22 per cent.) were later excised, fourteen of which had been disorganized when first seen. Retinal detachment was present post-operatively in 21 cases (5.6 per cent.) in which it had not been present pre-operatively. Intra-ocular haemorrhage was present pre-operatively in 71 cases (19 per cent.), and was first seen after operation in twelve cases $(3.2$ per cent.). The final visual results show that 157 cases ( $41 \cdot 7$ per cent.) achieved $6 / 18$ or better, and that 72 of these (19 per cent.) achieved $6 / 6$ or better.

These figures show that the two methods are almost equally effective in extracting the foreign body. The posterior gains slightly here, in that it proved successful in 29 cases where the anterior route had failed, and that in no case was the reverse true.

The final visual results of the whole series appear to show that the posterior route gives better results in spite of the fact that the cases with the foreign body in the anterior segment are expected to give the anterior route an advantage; however, against this must be weighed the higher incidence of cataract pre-operatively in those cases where the anterior route is used. 
It also appears at first that the incidence of post-operative intra-ocular haemorrhage and retinal detachment is very much higher in posterior than in anterior cases; but it should be noted that retinal detachment was seen pre-operatively in 4.51 per cent. of cases before the posterior route was used, compared with 1.33 per cent. before the anterior route was used. This indicates something of the false impression given by Table IX, on account of the successes with anteriorly placed foreign bodies which were relatively free of complications and in which good final results were obtained. In contrast, many of those posteriorly placed will already have caused retinal damage.

Therefore let us take cases where the pre-operative state is more truly comparable, e.g. where the foreign body was in the vitreous with no lens opacity. It is in this type of case, because of current controversy, that many surgeons will be doubtful which is the better route to choose. Thirty cases in which the foreign bodies were removed by the anterior route, and 59 in which it was removed by the posterior route fulfill these criteria, a total of 89 (Table X). It would appear therefore that there is a bias in favour of the posterior route in such cases in the present series. We find that retinal detachment was present pre-operatively in five cases $(8.5$ per cent.) where the

TABLE $X$

89 CASES OF FOREIGN BODY IN THE VITREOUS WITHOUT PRE-OPERATIVE LENS DAMAGE

\begin{tabular}{|c|c|c|c|c|c|c|}
\hline \multirow[t]{2}{*}{ Route $\quad \ldots$} & \multirow{2}{*}{$\cdots \quad \ldots$} & \multirow{2}{*}{$\cdots \quad \ldots$} & \multicolumn{2}{|c|}{ Anterior } & \multicolumn{2}{|c|}{ Posterior } \\
\hline & & & No. & $\%$ & No. & $\%$ \\
\hline \multirow{2}{*}{\multicolumn{2}{|c|}{ Retinal Detachment }} & Pre-operative & 3 & 10 & 5 & $8 \cdot 5$ \\
\hline & & Post-operative & 3 & 10 & 15 & $25 \cdot 5$ \\
\hline \multirow{2}{*}{$\begin{array}{c}\text { Other } \\
\text { Complications }\end{array}$} & Pre-operative & $\begin{array}{l}\text { Intra-ocular haemorrhage } \\
\text { Disorganization } \\
\text { Frank infection } \\
\text { Uveal prolapse }\end{array}$ & $\begin{array}{r}13 \\
1 \\
4 \\
3\end{array}$ & & $\begin{array}{r}21 \\
2 \\
2 \\
7\end{array}$ & \\
\hline & Post-operative & $\begin{array}{l}\text { Vitreous haemorrhage } \\
\text { (not present pre-operatively) } \\
\text { Cataract }\end{array}$ & $\begin{array}{l}2 \\
7\end{array}$ & $\begin{array}{r}6 \cdot 6 \\
23 \cdot 5\end{array}$ & $\begin{array}{r}13 \\
5\end{array}$ & $\begin{array}{r}22 \\
8 \cdot 5 \\
\end{array}$ \\
\hline \multicolumn{2}{|c|}{ Final Visual Result } & $\begin{array}{l}\text { Excision } \\
\text { Less than } 6 / 60 \\
6 / 60-6 / 24 \\
6 / 18-6 / 9 \\
6 / 6+ \\
\text { Not known }\end{array}$ & $\begin{array}{r}10 \\
2 \\
3 \\
8 \\
5 \\
2\end{array}$ & $\begin{array}{c}33 \cdot 3 \\
6 \cdot 6 \\
10 \\
26 \cdot 6 \\
16 \cdot 6 \\
6 \cdot 6\end{array}$ & $\begin{array}{r}9 \\
14 \\
3 \\
10 \\
21 \\
2 \\
\end{array}$ & $\begin{array}{r}15 \cdot 3 \\
23 \cdot 7 \\
5 \cdot 1 \\
16 \cdot 9 \\
35 \cdot 6 \\
3 \cdot 4\end{array}$ \\
\hline \multicolumn{2}{|c|}{ Percentage Results } & $\begin{array}{l}\text { Loss of eye or of useful } \\
\text { vision } \\
\text { Good final vision ( } 6 / 18 \text { or } \\
\text { better) } \\
\text { Full recovery ( } 6 / 6 \text { or better) }\end{array}$ & & $\begin{array}{l}40 \\
43 \cdot 3 \\
16 \cdot 6 \\
\end{array}$ & & \begin{tabular}{l|}
39 \\
$52 \cdot 5$ \\
$35 \cdot 6$ \\
\end{tabular} \\
\hline \multicolumn{3}{|l|}{ Total Cases } & 30 & & 59 & \\
\hline
\end{tabular}


posterior route was chosen, and in three cases (10 per cent.) in which the anterior route was used. The incidence of pre-operative intra-ocular haemorrhage in this group was 43 per cent. by the anterior route (thirteen cases) and 35.6 per cent. by the posterior route ( 21 cases).

While these figures appear to show that the posterior route cases in this sub-series are a little less damaged than the anterior route cases, the balance of complications is much less uneven than it is in the literature reviewed. The more serious complications of disorganization and uveal prolapse are found to occur in almost exact proportion to the number of cases operated by each route (disorganization in one anterior and two posterior cases, uveal prolapse in three anterior and seven posterior cases).

Operative Technique.-Before considering the post-operative complications and the final results, a few remarks on the technique used will be of value.

The Mellinger magnet was used in almost all cases. When the anterior route was used for a posterior segment foreign body, the direction of pull was arranged so that the foreign body was likely to be drawn from its position (localized by Sweet's method) through the zonule without damaging the lens or ciliary body. When iris bulging was seen the direction of force was altered so that the foreign body would be drawn into the anterior chamber from under the pupil margin. It was then deposited on the iris in a suitable position while a keratome incision was made at a position of choice (usually at 12 o'clock, unless there was already a gaping corneal wound through which the foreign body could be drawn). If iris damage occurred or the foreign body became entangled in the iris, an iridectomy was performed to remove the damaged portion.

By the posterior route, the sclera was exposed according to the localization of the foreign body. The position of the scleral section might be confirmed by preliminarymagnet applications. A scleral incision was made large enough to allow the foreign body to be extracted without encumbrance; no incision was made through choroid and retina, the foreign body being allowed to make its own incision through these structures. The magnet point would only be introduced within the eye if external application failed. Diathermy was almost never used; it was recorded in only one case in the present series, and I believe that it may have been used in up to five other cases only. Scleral suture was used at the discretion of the surgeon.

By both routes the weakest pull which would enable the foreign body to be removed was used, since it was felt this would reduce the damage to the eye at operation.

\section{Post-operative Complications}

(A) Retinal Detachment.-This occurred post-operatively in three anterior route removals (10 per cent.), in none of which it had been present pre-operatively. It occurred in fifteen posterior route removals $(25 \cdot 5$ per cent.), in four of which it had been present pre-operatively.

All three pre-operative detachments in which the anterior route was subsequently used had subsided at the first post-operative examination, only one of the five pre-operative detachments in the posterior removals subsided spontaneously. Thus it appears that three detachments (10 per cent.) were induced by anterior route removal, and eleven ( $18 \cdot 6$ per cent.) by posterior route removal.

The final visual results in these cases show that whichever route is used, the prognosis for good final vision is very poor if detachment occurs. The spontaneous reposition of the detachments seems to show that if detachment occurs pre- 
operatively the anterior route of removal offers the best chance of spontaneous recovery, and this would seem to be an indication for the anterior route. The numbers involved are small, however, and this point cannot be decided on the present series. Altogether nine of the 22 detachments which occurred in this sub-series became reposited spontaneously (41 per cent.): four of those were anterior (66.6 per cent. spontaneous recovery) and five posterior $(33.3$ per cent. spontaneous recovery).

Retinal detachment is the complication which one would expect to be more common in posterior route cases, and so it appears; but it is interesting to see that the anterior route is not immune from causing this complication.

(B) Vitreous Haemorrhage.-This was present post-operatively in thirteen posterior route cases ( 22 per cent.) and two anterior route cases $(6.6$ per cent.) where no intra-ocular haemorrhage was noted pre-operatively. Retinal detachment followed in four of the thirteen posterior removals. This complication increases the excision rate and reduces the number of cases finally achieving $6 / 6$ or better.

(C) Cataract.-The objection to the anterior route is the risk involved of causing damage to the lens. The protagonists of the anterior route minimize this complication (Trevor-Roper, 1944). Whiting (1951) is reported as saying that in all the cases which he had undertaken or observed, numbering some 400 , he had not seen the foreign body drawn through the lens on a single occasion. He thought that was a testimony to the technique, and that it was only a question of proper technique to avert mishap.

Cataract was noted post-operatively in the present sub-series in seven $(23.5 \mathrm{per}$ cent.) anterior removals, and in five $(8.5$ per cent.) posterior removals.

At first sight it seems odd that any cases should develop cataract after posterior route removal. Three of the five last mentioned were posterior-cortical concussion opacities which have been seen to develop after some delay. One was a localized opacity not noticed until just over 6 months after the injury and removal of the foreign body-the visual acuity in this eye has remained at better than $6 / 6$ for more than 2 years, and this lens opacity was possibly present before operation although it was not noted. The last case developed a siderotic cataract post-operatively; siderosis was present when the patient was first seen, and the foreign body was believed to have entered the eye 7 months previously.

In none of these cases does there seem to be any reason to believe that cataract was induced by the operation.

In the seven cases of post-operative cataract in which the anterior route was used it is possible that a lens opacity was present pre-operatively in two cases but not recorded; in the remaining five it was definitely stated to be absent pre-operatively and must therefore be taken as having been caused at operation. (Results: five excised; one less than 6/60; one 6/60-6/24). The size of the foreign body is only stated in one of these cases, in which its known minimum dimension was $2.5 \mathrm{~mm}$.

The zonular space between the equator of the lens and the ciliary body, through which foreign bodies are supposed to be drawn in this route of removal, is stated to be $1 \mathrm{~mm}$. wide. Surely it must be impossible to remove a foreign body of greater minimum dimension without damaging the lens, or, perhaps worse, the ciliary body. Even if only one dimension is greater there must be a considerable risk of damage to these delicate and important structures.

The remarks of Brownlie (1915) are worth quoting in this context: he said that in many cases the foreign body, instead of sliding round the edge of the lens and perforating the zonule " edge first", engages " broadside on" and becomes "locked" and firmly fixed in the circumlental (zonular) space. 
Discussion.-So we see that post-operative retinal detachment and vitreous haemorrhage, both grave complications, occur more frequently after posterior route extraction in a comparable series. We also see that in the present sub-series post-operative cataract was induced in possibly 23.5 per cent. and certainly over 16 per cent. of the anterior extractions. As a percentage of all anterior removals this complication will appear, as Trevor-Roper (1944) says, " not very important" ( $1 \cdot 33$ per cent.), but in many the position of the foreign body is such that the lens is unlikely to be damaged by its removal. It is without statistical significance that Whiting (1951) said that he had never seen this complication in his experience of some 400 cases, but that the foreign body slid round without damaging the lens. It seems that, on some occasions at least, damage must be expected from a sharp-edged body approaching such a delicate structure.

Whiting said it was only a question of proper technique to avert mishap, but in the five cases recorded in the present sub-series there is nothing to indicate faulty technique, except that the size of foreign body was not considered carefully enough in one case.

Gundersen (1947), who advocates the anterior route in these cases, says, and it is interesting to remember Whiting's comment here, that:

no surgeon at the Massachusetts Eye and Ear Infirmary could recall such an accident (injury to the clear lens) before the war, but I have been told that it occurred in two successive cases. In the first a small foreign body $(2 \times 2 \times 3 \mathrm{~mm}$. $)$ and in the second a large one $(4 \times 5 \times 6 \mathrm{~mm}$. traversed the clear lens causing cataract.

In reviewing these complications one wonders which is the worst. As will be seen later, retinal detachment and cataract will have almost equal effect on visual function, the excision rate being rather higher in cases of cataract. These complications cause the bulk of disagreement on the relative merits of the two routes.

It seems to me that the final result in the whole group is more important. Which route, in spite of the complications to which it is prone, will give the best results?

The visual results (Table $\mathrm{X}$ ) show that the excision rate is more than twice as high if the anterior route is chosen and it is difficult to argue in favour of the anterior route in the light of this surprising difference. For a long time the posterior route has been decried because the excision rate was higher; possibly this striking reversal is due to better asepsis and more effective therapeutic agents.

In eyes in which the final result is "bad", using the grouping of Desvignes and Boudon (1947) of those excised and those with less than 6/60 retained vision, the percentages are almost equal for the two groups. Some surgeons may say that as these are all useless eyes they would be safer removed. On the other hand, many retain a good cosmetic appearance and all in this series have remained safe from sympathetic ophthalmia. Those achieving good final vision (6/18 or better) show that the posterior route is giving significantly better results, just over twice as many posterior route extractions achieving full recovery (6/6 or better).

In the present group there was no aphakia where the final vision was good: only three cases were finally aphakic, one was excised, one had final vision less than $6 / 60$, and the third had vision between $6 / 60$ and $6 / 24$.

A comparison of pre-operative and post-operative vision shows that 30.3 per cent. posterior and $28 \cdot 6$ per cent. anterior removals had improved vision postoperatively, $30 \cdot 3$ per cent. posterior and 50 per cent. anterior were worse, and $39 \cdot 3$ per cent. posterior and 21.4 per cent. anterior retained the same vision. These 
figures show that while each case must be considered individually, there is less risk of loss of the eye and a better chance of return to normal function if the posterior route is used.

I think it can be said that no surgeon will disagree with the use of the posterior route where the anterior route has failed. In the present series this was attempted in 39 cases, and in 29 of them proved successful. In 27 of these the posterior route was successful at its first attempt, and in one the anterior route had previously been tried three times.*

When a lens opacity is already present in a case of vitreous foreign body, many surgeons who normally favour the posterior route in the absence of lens opacity would feel that there was no contraindication to the anterior route since the damage was already done. It should be remembered, however, that many lens opacities will remain stationary, the capsule sealing itself so that aqueous is prevented from reaching the lens fibres. In other cases the lens matter may be generally opaque and yet insulated from the aqueous so that no absorption takes place. If a foreign body is drawn through this lens and causes the lens matter to be freely accessible to the aqueous, the eye will become more iftitable. In view of the danger of sympathetic ophthalmia and the difficulty of ascertaining in such cases whether the irritation is entirely due to lens matter, it may be decided that it is safer to excise. Finally, the vitreous face may be damaged and vitreous become mixed with lens matter in the anterior chamber; this may cause the eye to settle badly.

In the present series, 24 foreign bodies were removed by the posterior route and 39 by the anterior route. This shows a reversal of the favoured route in comparison with the previous sub-series. The visual results (Table XI) again show a marked increase in the excision rate in the anterior route cases. Those finally

TABLE XI

63 CASES OF FOREIGN BODY IN VITREOUS WITH PRE-OPERATIVE LENS DAMAGE

\begin{tabular}{|c|c|c|c|c|c|c|}
\hline \multirow{2}{*}{ Route } & \multirow[b]{2}{*}{$\cdots$} & \multirow{2}{*}{$\cdots$} & \multicolumn{2}{|c|}{ Anterior } & \multicolumn{2}{|c|}{ Posterior } \\
\hline & & & No. & $\%$ & No. & $\%$ \\
\hline \multirow{2}{*}{ Complications } & Pre-operative & Intra-ocular haemorrhage & 5 & 13 & 2 & $8 \cdot 3$ \\
\hline & Post-operative & $\begin{array}{l}\text { Vitreous haemorrhage } \\
\text { Retinal detachment }\end{array}$ & $\begin{array}{l}4 \\
1\end{array}$ & $\begin{array}{c}10 \cdot 26 \\
2 \cdot 8\end{array}$ & $\begin{array}{l}4 \\
2\end{array}$ & $\begin{array}{r}16 \cdot 6 \\
8 \cdot 3\end{array}$ \\
\hline \multicolumn{2}{|c|}{ Final Visual Result } & $\begin{array}{l}\text { Excised } \\
\text { Less than } 6 / 60 \\
6 / 60-6 / 24 \\
6 / 18-6 / 9 \\
6 / 6+ \\
\text { Not known }\end{array}$ & $\begin{array}{r}10 \\
15 \\
5 \\
5 \\
3 \\
1\end{array}$ & $\begin{array}{l}26 \cdot 4 \\
39 \cdot 6 \\
13 \cdot 2 \\
13 \cdot 2 \\
8\end{array}$ & $\begin{array}{c}\text { Nil } \\
10 \\
5 \\
5 \\
4 \\
-\end{array}$ & $\begin{array}{l}\overline{42} \\
21 \\
21 \\
16\end{array}$ \\
\hline \multicolumn{2}{|c|}{ Percentage Results } & $\begin{array}{l}\text { Loss of eye or of useful } \\
\text { vision } \\
\text { Good final vision ( } 6 / 18 \text { or } \\
\text { better) } \\
\text { Full recovery ( } 6 / 6 \text { or better) }\end{array}$ & . & $\begin{array}{c}66 \\
21 \cdot 2 \\
8\end{array}$ & & $\begin{array}{l}42 \\
37 \\
16\end{array}$ \\
\hline \multicolumn{2}{|l|}{ Total Cases } & & 39 & & 24 & \\
\hline
\end{tabular}

* Admittedly, the Mellinger magnet was used, and anterior route extraction might have been successful had the more powerful Haab magnet been available, but the power of a magnet is very difficult to assess. Some give a very strong pul which is not sustained (Lancaster, 1938). Sweet's hand magnet was stated to be stronger than Haab's giant magnet at $2 \mathrm{~mm}$., equal at $5 \mathrm{~mm}$., and weaker at greater distances. 
reaching $6 / 6$ or better are about equal in the two groups, and, apart from the difference in the excision rate, the comparison of pre-operative and post-operative vision favours both routes equally.

In a number of cases the extra disturbance of lens matter at removal has led to a stormy post-operative course. Some of the more severely damaged eyes will have gaping corneal wounds, damaged lenses, and since the anterior route will certainly be chosen, the excision rate may then be expected to be higher.

In such cases the present series gives no clear indication for either route, unless the lens opacity is small and likely to remain localized, when the posterior route will prove best.

The foregoing discussion gives rise to certain indications for one or other route:

\section{(1) Vitreous Foreign Bodies with a Clear Lens}

(a) The posterior route of removal is clearly the one of choice for foreign bodies greater than $1 \mathrm{~mm}$. in any dimension.

(b) The presence of retinal detachment as a pre-operative complication contraindicates the posterior route.

(c) The presence of intra-ocular haemorrhage as a pre-operative complication contraindicates the posterior route.

(d) Final visual results are better if the posterior route is used, and conversely the risk of excision is greater after anterior route extractions.

(e) Retinal detachment and intra-ocular haemorrhage are more common after posterior route extractions.

(f) Injury may occur during anterior route removal to a previously clear lens.

\section{(2) Vitreous Foreign Bodies with a Damaged Lens}

If the lens opacity is small and likely to remain localized the posterior route gives more favourable results.

In applying these conclusions the danger of further complications leąding to bad final results could be reduced.

\section{Pre-Operative Complications in Present Series}

(A) Uveal Wounds.-These were present without prolapse in 252 cases, most often consisting of a simple perforation of the iris, ciliary body, or choroid. Prolapse of the uvea was present in a further 46 cases. Thus damage to uveal tissues occurred in 298 cases (53.7 per cent. of the whole series). In the absence of prolapse, excision was necessary in 51 cases $(20.4$ per cent.). This compares very closely with the figure of 20 per cent. for the whole series. In the 46 cases with uveal prolapse (8.29 per cent. of the whole series), excision was required in 23 cases (50 per cent.). It therefore appears that the presence of uveal damage does not alter the prognosis of the case unless the damage is severe or prolapse present.

The finding of uveal prolapse cannot be regarded as evidence against the presence of an intra-ocular foreign body but only suggestive that the foreign body if present is large. The 46 cases ( 8.29 per cent.) with uveal prolapse form a considerable proportion in this series. The size of foreign body is known in nine, the largest being 40 and the smallest $2.7 \mathrm{c} . \mathrm{mm}$. (average $18 \mathrm{c} . \mathrm{mm}$.). Thus the foreign bodies were considerably larger than for the series as a whole. 
This relatively high incidence of uveal prolapse is in direct contradiction to the findings of Verhoeff (1932), who writes:

many years ago an astute observer, whose name I cannot recall, made the observation that incarceration of the iris in a corneal wound was proof that there was no foreign body within the eye. I have met with few exceptions to this rule.

Verhoeff's statement is quoted by McBride (1949), who holds the same opinion, and Sellas (1949), referring to small corneal wounds, has come independently to the same conclusion:

This sign, which I have not seen described elsewhere, is quite constant, above all if the wound has not been manipulated, and it has served me as orientation in many cases.

In the present series, however, twenty of the 46 cases of uveal prolapse had purely corneal wounds. The size of the wound could be estimated in fifteen cases, all of which had iris prolapse into or through the wound; ten may be regarded as small (less than $3 \mathrm{~mm}$.) and five as large. The observation of iris prolapse in a corneal wound should, therefore, not be regarded as evidence against the presence of an intra-ocular foreign body.

(B) Cataract.-This complication was present at the first examination of 219 cases (39.46 per cent.);* 48 subsequently required excision of the injured eye (this is 22 per cent. of all cases with this complication and therefore shows only a slight increase in the excision rate when compared with the series as a whole), 51 subsequently became aphakic, and 120 retained the lens damaged to a greater or lesser extent. The opacities remain stationary with retention of useful vision in a considerable number of cases.

(C) Inflammation.-A marked inflammatory reaction was present in 56 cases (10.1 per cent.) when first seen; in the majority of these $(87.5$ per cent.) this consisted of a hypopyon or other severe iritis. There were fourteen excisions in this group ( 25 per cent.) but the final visual acuities in the eyes retained show the same distribution as in the series as a whole.

The excision rate shows an increase in this group. The prognosis may therefore, be said to be worse in the presence of this complication.

(D) Retinal Detachment.-This was present in eleven cases pre-operatively ( 2 per cent.). It appears that this complication arose only when the foreign body was localized in the posterior segment and the retina was likely to have suffered direct damage. Five foreign bodies were removed by the posterior route, four by the anterior, and two were retained. The results favour the anterior route for this type of case. $\dagger$

(E) Intra-ocular Haemorrhage.-This is a serious complication, and was present at the first examination in 109 cases (19.64 per cent.), excision being necessary in 37 (34 per cent.). Retinal detachment also occurred at some stage in 22 of the injured eyes with this complication $(20 \cdot 2$ per cent.). In half the cases the haemorrhage was found to be absorbed at the first post-operative examination, but it was still present in the remainder. In the cases in which absorption took place rapidly, the haemorrhage was presumably only into the anterior chamber, but this is not certain from my records.

In the 55 cases with unabsorbed haemorrhage, many of which will have been into the vitreous, fifteen retinal detachments occurred $(27 \cdot 3$ per cent.). 
The frequent association of retinal detachment and intra-ocular haemorrhage in the present series points to a causal relationship. It seems probable that a retinal injury associated with a vitreous disturbance due to haemorrhage forms a strong predisposition to detachment. This view is also held by Sellas (1949).

In seven of the eleven cases in which retinal detachment was present before operation, intra-ocular haemorrhage was also present (63.6 per cent.).

(F) Disorganization.- Nineteen eyes were damaged to the extent of disorganization when first examined. As is to be expected, the excision rate is extremely high; seventeen were excised (89.5 per cent.) and one of the remaining two had a final visual acuity of less than $6 / 60$. The other eye, however, regained $6 / 6$ vision; in this case, although there had been much iris damage and intra-ocular haemorrhage, the lens had escaped undamaged. Iridectomy was performed, an anterior synechia remained post-operatively and a vitreous haemorrhage absorbed without incident. The follow-up period in this case was between 3 and 6 months after operation.

Among the pre-operative complications of the injury it may therefore be said that the presence of severe damage, as assessed by the occurrence of uveal prolapse or disorganization, carries with it a grave prognosis for the retention of the eye. The risk of excision is also increased in the presence of intra-ocular haemorrhage (34 per cent.), siderosis (28 per cent.), retinal detachment (27 per cent.), and inflammatory reaction (25 per cent.). However, the presence of cataract ( 22 per cent. excision) and uveal damage without prolapse (20.24 per cent. excision) do ss not materially alter the excision rate.

The visual results in the eyes retained (Table XII) show that uveal prolapse and cataract pre-operatively carry the worst prognosis from this point of view. On the other hand the visual results in cases with uveal wounds, inflammation, and intra-ocular haemorrhage show much the same distribution as the series as a whole.

TABLE XII

FINAL VISUAL RESULTS IN 444 CASES WITH CERTAIN PRE-OPERATIVE CQMPLICATIONS (EXCISIONS EXCLUDED)

\begin{tabular}{l|c|c|c|c|c|c}
\hline \multirow{2}{*}{ Complication } & \multicolumn{3}{c|}{ Final Visual Result } & \\
\cline { 2 - 7 } & $\begin{array}{c}\text { Less than } \\
6 / 60\end{array}$ & $6 / 60-6 / 24$ & $6 / 18-6 / 9$ & $6 / 6+$ & Uncertain & Total \\
\hline Uveal wounds & 52 & 21 & 53 & 60 & 15 & 201 \\
Uveal prolapse & 12 & 2 & 5 & 2 & 2 & 23 \\
Cataract & 72 & 27 & 34 & 17 & 21 & 171 \\
Inflammation & 7 & 6 & 11 & 10 & 8 & 42 \\
Retinal detachment & 3 & 1 & 3 & 1 & 7 & 8 \\
Intra-ocular haemorrhage & 19 & 7 & 22 & 17 & 8 & 73 \\
\hline Total Complications* & 165 & 64 & 128 & 107 & 54 & 518 \\
\hline Total Cases & 111 & 44 & 120 & 120 & 49 & 444 \\
\hline
\end{tabular}

It may be added therefore that a uveal wound without prolapse does not alter the general prognosis in cases of intra-ocular foreign body, and that 
the presence of cataract does not much increase the risk of losing the eye, but does considerably reduce the possibility of good final vision.

\section{Operative and Post-Operative Complications in Present Series (TABLE XIII)}

(A) Iridectomy is necessary in a large number of anterior route removals and is a disadvantage of the route. In some, iris damage necessitating iridectomy will have been caused by the original injury; but this does not account for most of them.

(B) Cataract and Aphakia are expected to occur more frequently in anterior removals, as most of these will have had cataract pre-operatively and this will have been considered a factor in favour of the anterior route (see p. 89).

Results in the present series were slightly better where the posterior route was used to remove the foreign body even where cataract was present. Cataract can be caused at operation by the anterior route, but that this is uncommon in a complete series including foreign bodies in all parts of the globe is clear from the fact that though cataract was noted in 219 cases pre-operatively it was found in only 212 cases after operation. The difference in these figures is largely due to the cases in which the foreign body was removed in the lens at cataract extraction.

(C) Hyphaema occurred much more frequently after anterior removals and Vitreous Haemorrhage after posterior removals. This seems to favour the anterior route, in that hyphaema is not so serious a complication. These groups are not really comparable, since all the posterior route extractions refer to posteriorly placed foreign bodies, when vitreous haemorrhage is more likely to occur (pp. 85-86).

TABLE XIII

COMPLICATIONS OCCURRING AT AND AFTER OPERATION

\begin{tabular}{|c|c|c|c|c|c|}
\hline \multirow{2}{*}{ Complication } & \multicolumn{2}{|c|}{$\begin{array}{l}\text { Anterior Route } \\
\text { Operation }\end{array}$} & \multicolumn{2}{|c|}{$\begin{array}{l}\text { Posterior Route } \\
\text { Operation }\end{array}$} & \multirow{2}{*}{$\begin{array}{c}\text { Both } \\
\text { Routes }\end{array}$} \\
\hline & No. & $\%$ & No. & $\%$ & \\
\hline $\begin{array}{l}\text { Iridectomy } \\
\text { Cataract } \\
\text { Aphakia } \\
\text { Hyphaema } \\
\text { Vitreous haemorrhage } \\
\text { Retinal detachment } \\
\text { Inflammation } \\
\text { Sympathetic ophthalmia } \\
\text { Anterior synechia } \\
\text { Subluxation of lens }\end{array}$ & $\begin{array}{r}91 \\
176 \\
51 \\
49 \\
30 \\
16 \\
94 \\
1 \\
41 \\
7\end{array}$ & $\begin{array}{c}24 \cdot 5 \\
47 \cdot 4 \\
13 \cdot 7 \\
13 \cdot 0 \\
8 \\
4 \cdot 3 \\
25 \cdot 3 \\
\frac{11}{2}\end{array}$ & $\begin{array}{r}3 \\
38 \\
5 \\
4 \\
42 \\
25 \\
26 \\
\text { nil } \\
6 \\
2\end{array}$ & $\begin{array}{l}2 \cdot 3 \\
29 \\
3 \cdot 8 \\
3 \\
31 \cdot 8 \\
19 \\
20 \\
-4 \cdot 5 \\
1 \cdot 5\end{array}$ & $\begin{array}{r}1 \\
22 \\
1 \\
2 \\
7 \\
5 \\
8 \\
\text { nil } \\
2 \\
\text { nil }\end{array}$ \\
\hline $\begin{array}{l}\text { *Hypotony } \\
\text { * Phthisis } \\
\text { *Chorio-retinal scar } \\
\text { * Glaucoma } \\
\text { *Vitreous loss }\end{array}$ & $\begin{array}{r}32 \\
6 \\
13 \\
27 \\
8\end{array}$ & $\begin{array}{l}9 \cdot 3 \\
1 \cdot 5 \\
3 \cdot 8 \\
8 \\
2 \cdot 3\end{array}$ & $\begin{array}{r}10 \\
1 \\
29 \\
2 \\
17\end{array}$ & $\begin{array}{l}8 \cdot 6 \\
0 \cdot 86 \\
25 \\
1 \cdot 7 \\
14 \cdot 5\end{array}$ & $\begin{array}{r}\text { nil } \\
\text { nil } \\
6 \\
4 \\
3\end{array}$ \\
\hline
\end{tabular}

(Thirteen cases, where no attempt was made to remove the foreign body or the method used was uncertain, have been excluded from this Table).

Of the total of 542 records, the anterior route was used in 371 cases, the posterior route in 132 , and both routes in 39.

*These complications were not recorded in most 1946 cases; the number of cases and percentages have been taken from 343 anterior route cases and 117 posterior route cases. 
(D) Retinal Detachment is also more frequent in posterior route cases, but the same care should be taken in assessing this point.

(E) Inflammation occurred about equally in the two groups.

This is surprising in view of the criticism levelled at the posterior route by a number of authors including Goulden (1908) and Trevor-Roper (1944).

(F) Sympathetic Ophthalmia occurred in only one case in the whole series; it is difficult to explain the very low incidence, except that this is a danger of which we were fully aware, and that in this hospital excision is advised when there is delay in settling post-operatively and final vision is unlikely to be useful. However, in spite of this, the annual excision rate is falling. It therefore seems possible that the improvement in aseptic technique and the better control of infection generally, have a bearing on the reduction of sympathetic ophthalmia.

The literature shows that sympathetic ophthalmia, although always a serious potential danger, has very seldom become a fact in recent years even in the military series. In a recent civilian series, Sellas (1949) reported sympathetic ophthalmia in only one case out of 150,000 injuries (including 414 intra-ocular foreign bodies).

(G) Anterior Synechiae occurred more often in anterior route cases. The remarks on "Iridectomy" above apply here also.

(H) Glaucoma also'complicated the anterior route cases more frequently. This is largely due to swollen lens matter coming forward into the anterior chamber, but an additional factor in some cases may be damage to the iris and to the angle of the anterior chamber.

Wilder (1947) stated that in her experience glaucoma was a rare complication in the 731 excised eyes which she examined.

(I) Chorio-Retinal Scarring was more commonly seen in posterior route cases and it is surprising that it was not noted even more frequently. In some cases this may have been due to the site of removal being too far forward to be seen with the ophthalmoscope.

(J) Vitreous Loss also occurred more often in posterior route cases, but care must be taken in making a decision on this point because the figures are not strictly comparable. A small vitreous loss as the foreign body is on the point of extraction is common, but it can be controlled immediately by drawing tight a pre-placed scleral suture. It is hardly a serious complication when final results are considered.

The remaining complications listed refer to small numbers and show no significant difference between the two groups.

Retinal Detachment. - Where retinal detachment was present preoperatively the results are overwhelmingly in favour of the anterior route of removal (Table XIV). An examination of each individual case seems to show that the reaction produced by the posterior route operation regularly results in prolonging the presence of retinal detachment. Furthermore, there is an increased risk of vitreous haemorrhage arising from the incised tissues at operation which militates against spontaneous reposition.

I was surprised that so many detachments subsided spontaneously (fifteen out of the total of 54 cases, $27 \cdot 7$ per cent.). This satisfactory outcome 
TABLE XIV

ANALYSIS OF RETINAL DETACHMENTS

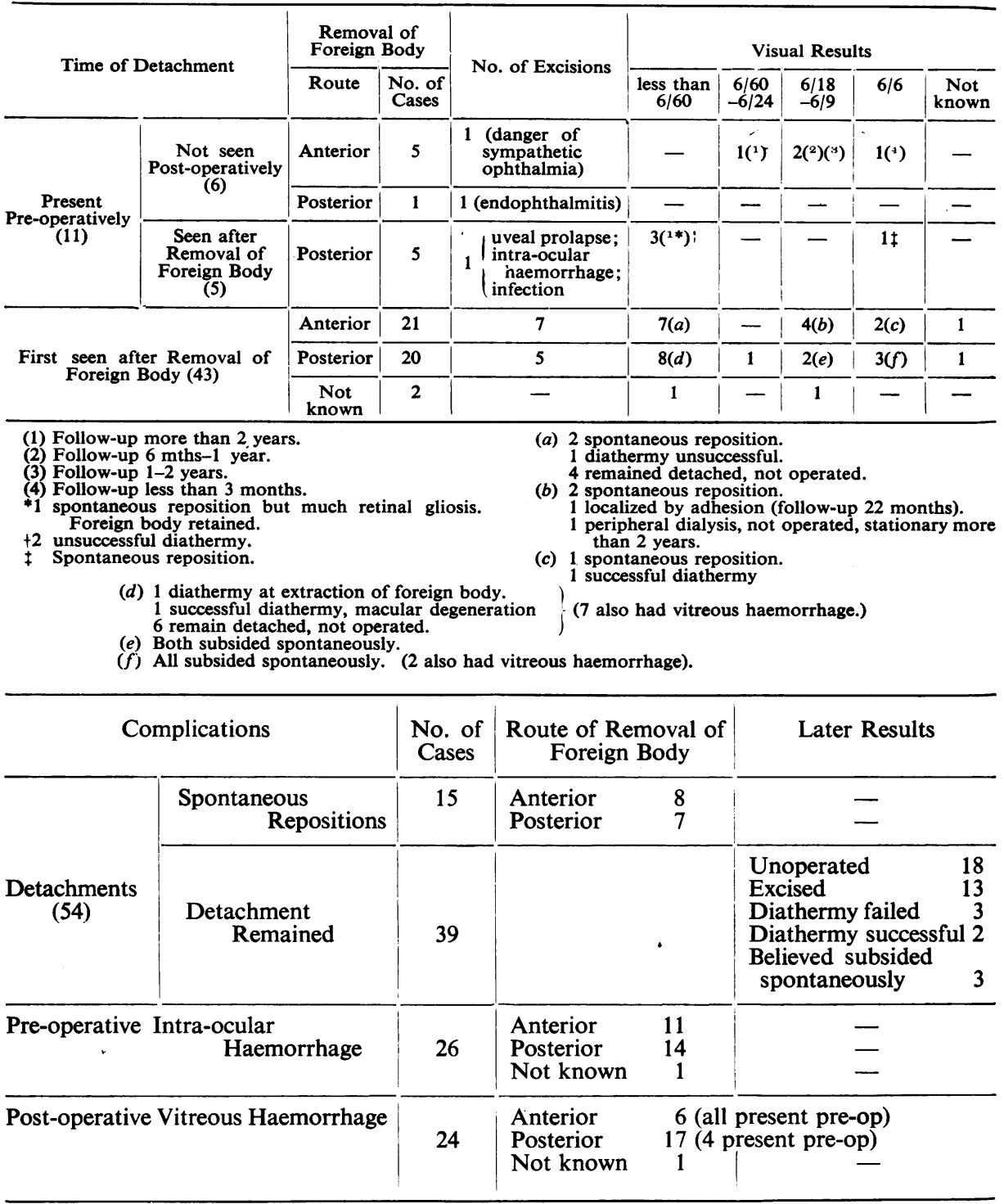

was equally common whichever route was used. On the other hand, where diathermy operation for detachment was attempted, the results were poor (three unsuccessful cases and two successful); but it may be expected that, with the improved technique of retinal detachment surgery now available, the percentage of successful results will be greater in the future in this as in other types of detachment. Similarly, the high proportion of cases (12) in which no attempt was made to re-attach the retina possibly reflects the poor prog- 
nosis in the early years of the present series. It seems unlikely that many cases with retinal detachment will now remain unoperated. In two cases however, in which detachment is present, it has remained localized for a long period with retention of good vision; in such cases operation does not seem justified.

Visual Results.-The final results are disappointing, and even where reattachment occurred either spontaneously or by operation, permanent damage to the macular region had often been done.

A review of cases with this complication may show an improvement in visual results* in the next few years, but unless a marked improvement occurs retinal detachment must still be regarded as serious.

Every precaution must be taken to avoid detachment, but it must be remembered that in general better visual results are found in posterior route removals of posteriorly placed foreign bodies.

For this reason I believe that this complication should not be considered a contraindication to the use of the posterior route. First, rather, we should exclude the posterior route in those cases where the risk of detachment is greater, i.e. in the presence of intra-ocular haemorrhage and when detachment is already present as a result of the injury. Secondly, the use of the anterior route when a foreign body is entangled in the retina has been criticized by one author as likely to cause a retinal tear and detachment. Unless the foreign body can be seen, this point cannot be decided and unfortunately in most cases the foreign body is not seen.

Diathermy.-This has been advocated by a number of authors as part of the operative procedure in removal by the posterior route. Their reasons vary: most advocate it to seal the operational tear in the retina and prevent detachment (Stallard, 1946; Bellows, 1947; Lucic, 1948). Lancaster (1938) advises using a diathermy knife as a method of making a bloodless scleral incision, and Gundersen (1947) and Stallard (1946) advise it to avoid the complication of intra-ocular haemorrhage. Kraus and Briggs (1945) point out that dosage must be carefully controlled, since excessive diathermy may produce vitreous opacities and traction bands leading to detachment; they advise diathermy for a limited area " to avoid complications", but do not specify the complications to be avoided thereby.

Diathermy was not used in an appreciable number of cases in the present series; it is only known to have been used in one case, in which vitreous haemorrhage subsequently occurred and detachment followed. Most cases in which the posterior route was used show a firm adhesion between the retina and the choroid at the site of removal. Diathermy would be unlikely to increase the firmness of adhesion in these cases, but would cause rather more widespread scarring. Jameson Evans (1951) regards this as a contraindication to its use, considering that further unnecessary damage is inflicted upon an already severely damaged eye. In support of this statement I find that the incidence of retinal detachment appears no greater in the present series than in others, except that of Sherman (1939), who records a low incidence of retinal detachment, and seems not to have used diathermy. *The results are, in fact, better as shown by Sellas (1949), who gives notes on five detachments, three of which were
" cured perfectly by diathermy". 
The highest incidence of retinal detachment that $I$ have found $(12 \cdot 3$ per cent.) is in fact in the military series of Bellows (1947), who says:

The sclerotomy wound was always ringed with diathermy applications as a safeguard against retinal detachment.

It must be noted that Bellows's series cannot fairly be compared with a civilian series.

Vitreous Haemorrhage.-From the records in the present series it seems clear that vitreous haemorrhage is often associated with later retinal detachment, and that it is sometimes produced at posterior route operation.

The risk of vitreous haemorrhage at operation may be reduced by so placing the scleral incision that large vessels are less likely to be damaged. The magnet electrode should not be introduced within the scleral wound unless the foreign body cannot otherwise be extracted. (This advice is given by Sweet, 1906; Stieren, 1932; and Sherman, 1939. The last suggests that this point in technique may account for the low incidence of retinal detachment in his series.)

Finally, properly controlled diathermy should materially reduce the risk of vitreous haemorrhage, and appears to be indicated for this reason, thereby indirectly and not directly reducing the risk of detachment. Using the diathermy knife to make the scleral incision seems a good way of satisfying this requirement.

\section{CONCLUSIONS*}

(1) As is to be expected in an industrial community, the highest incidence of intra-ocular foreign bodies is found between the ages of 21 and 40 .

(2) While the majority of intra-ocular foreign bodies in civilian practice are magnetic, there has been a slight increase in recent years in the percentage of non-magnetic foreign bodies. The visual results in cases with retained non-magnetic foreign bodies are better than those in the series taken as a whole, but the excision rate is higher.

Brass and copper often produce severe inflammation necessitating early excision, but if they are retained without inflammation or are easily removed the prognosis differs little from that of magnetic foreign bodies. Thus, contrary to most published opinions, a satisfactory outcome is not rare.

(3) With the increase in size of the foreign body there is an increase in frequency of uveal prolapse and intra-ocular haemorrhage. Cases with large foreign bodies show post-operative cataract more often than pre-operative cataract. As the size of the foreign body increases, penetration is greater, and prognosis as regards excision and final visual acuity is worse. As the size of the foreign body increases there is also a statistically significant change in the relative frequency of the eye involved. With small foreign bodies the right eye is predominantly affected and with large ones the left.

(4) Anterior-segment foreign bodies have a much better prognosis than posterior-segment foreign bodies. Prognosis in the present series was worst in cases where the foreign body lodged in the uveal tract, excluding the iris.

(5) There has been a progressive reduction in the rate of excision during

*Certain findings which appeared in the thesis upon which this paper is based are omitted here because they agree with most previous published series and would result in unnecessary repetition. 
the past 20 years, a change which must lead to a modification of previous views, especially with regard to the criticisms of the posterior route of extraction. This decrease appears to be due to better control of infection. Post-operative infection is very much reduced, and is less frequent in posterior than in anterior extractions, a finding contrary to the views of Goulden (1907-8) and Trevor-Roper (1944). Panophthalmitis, once a common reason for excision, and sympathetic ophthalmia, are fortunately now rare complications.

(6) While a long follow-up period is desirable, there is no satisfactory evidence to show that deterioration is to be expected over such a period. Certain inaccuracies are likely to occur in recording end-results after short follow-up periods, but far greater inaccuracies will occur if series are reduced to include only cases with a long follow-up period. It is, therefore, suggested that series should remain complete, but that the length of follow-up before the end-result is assessed should be recorded.

(7) The difficulty in removing a foreign body increases progressively as time passes, but this is not apparent within a few hours or even a few days. Accurate localization should not be neglected for the sake of speed.

(8) In a comparable series of posterior-segment cases it becomes clear that the anterior route is preferable in those with pre-operative retinal detachment, intra-ocular haemorrhage, or severe lens damage. Injury may occur to a previously clear lens during anterior route removal. Retinal detachment and intra-ocular haemorrhage are more common after posterior route extractions; but even so, the visual results are better and the excision rate lower by this route.

It is highly inadvisable to remove vitreous foreign bodies greater than $1 \mathrm{~mm}$. in any dimension by the anterior route, especially when the lens is undamaged.

(9) No evidence has been found in the literature or in the results of the present series to support the view that an improvement of vision is likely to take place in cases of siderosis after the foreign body is removed. However, cataract extraction in cases with siderotic cataract has often led to a satisfactory result. These findings agree with those of Verhoeff (1932) but disagree with those of Gray Clegg (1915) and Cridland (1916).

(10) The finding of uveal prolapse should not be regarded as evidence against the presence of an intra-ocular foreign body. A uveal wound without a prolapse does not alter the general prognosis. The presence of cataract does not markedly increase the risk of loss of the eye but considerably reduces the possibility of good final vision.

(11) Retinal detachment is unlikely to occur unless the foreign body is in the posterior segment. The very frequent association of retinal detachment and intra-ocular haemorrhage points to a causal relationship. This also is the opinion of Sellas (1949). Retinal detachments subside spontaneously 
in a surprising number of cases (27.7 per cent. of those in the present series). In the remaining cases operation is now more effective in repositing the retina, but every effort must be made to avoid detachment. In particular, steps should be taken to reduce the risk of vitreous haemorrhage at operation.

\section{SUMMARY}

A series of 555 cases of intra-ocular foreign body is reviewed. Orbital foreign bodies are excluded, and corneal and scleral foreign bodies are also excluded unless penetration occurred. The findings are discussed and certain conclusions are reached. Special attention is given to prognosis.

Acknowledgments are due to the consultant staff of the Birmingham and Midland Eye Hospital for permission to use their records; to the members of the administrative staff for their co-operation in searching for records and preparing certain lists, and to Dr. John Waterhouse for statistical advice. I am especially grateful to Mr. Philip Jameson Evans for his advice and encouragement.

\section{REFERENCES}

AllPORT, F. (1925). Amer. J. Ophthal., 8, 472.

ANDERSON, W. A. (1951). Trans. ophthal. Soc. U.K., 71, 252, 255.

Barkan, O., and Barkan, H. (1927). Amer. J. Ophthal., 10, 919.

Bellows, J. G. (1947). Ibid., 30, 309.

Brownle, W. B. (1915). Ophthalmoscope, 13, 316.

Clegg, J. Gray (1915). Ibid., 13, 501. (1926). Trans. ophthal. Soc. U.K., 46, 179.

Collins, E. Treacher (1916). Ibid., 36, 63. [Abs. Thomson, E. (1917). B.J.O., 1, 629].

Cridland, A. B. (1916). Ibid., 34, 63. [Abs. Thomson, E. (1917). B.J.O., 1, 632, 637]. - (1926). Ibid., 46, 178. (1933). Ibid., 53, 438.

Davidson, M. (1933). Amer. J. Ophthal., 16, 331.

Desvignes, P., and Boudon, C. (1947). Arch. Ophtal., n.s., 7, 28.

Duggan, W. F. (1933). Arch. Ophthal. (Chicago), 10, 768.

Evans, P. JAMESON (1951). Trans. ophthal. Soc. U.K., 71, 251, 254.

Goulden, C. (1908). Roy. Lond. Ophthal. Hosp. Rep., 17, 301.

Gulliver, F. D. (1942). Arch. Ophthal. (Chicago), 28, 896.

Gundersen, T. (1947). Trans. Amer. Acad. Ophthal. Otolaryng., 51, 604.

Kiehle, F. A. (1932). Arch. Ophthal. (Chicago), 7, 180.

Kraus, J., and BRIGgs, W. A. (1945). British Journal of Ophthalmology, 29, 557.

LANCASTER, W. B. (1938). Amer. J. Surg., 42, 14.

LISTER, W. T. (1916). Trans. ophthal. Soc. U.K., 36, 164.

LuCic, H. (1948). Calif. Med., 69, 114.

MCBRide, J. P. (1949). Amer. J. Ophthal., 32, 1255.

MoRAX, V. (1916). Ann. Oculist. (Paris), 153, 456. [Abs. Souter, W. C. (1917). B.J.O., 1, 58]. , and Moreau, F. (1916). Ibid., 153, 321. [Abs. Coulter, R. J. (1917). B.J.O., 1, 124].

Parsons, J. H. (1916). Trans. ophthal. Soc. U.K., 36, 69.

Roper-Hall, M. J. (1952). Ann. Oculist. (Paris), 185, 468.

Sellas, J. (1949). Arch. Soc. Optal. Hispano-Amer., 9, 1178.

Sherman, E. S. (1939). Amer. J. Ophthal., 22, 1368.

SHOEMAKER, W. T. (1919). Ibid., 2, 590.

SOMERSET, E. J., and SEN, K. (1948). British Journal of Ophthalmology, 32, 13.

Stallard, H. B. (1946). "Eye Surgery", p 389. Wright, Bristol. (1947). British Journal of Ophthalmology, 31, 12.

StIEREN, E. (1913). Ophthal. Rec., 22, 533. (1932). Amer. J. Ophthal., 15, 1120.

SWEET, W. M. (1914). Ophthalmology, 10, 272.

TREVOR-ROPER, P. D. (1944). British Journal of Ophthalmology, 28, 361.

VERHOEFF, F. H. (1932). Amer. J. Ophthal., 15, 685.

WhITEHEAD, A. L. (1916). Trans. ophthal. Soc. U.K., 36, 63 [Abs. Thomson, E. (1917). B.J.O., 1, 629].

WhITING, M. H. (1951). Ibid., 71, 251.

Wilder, H. C. (1947). Trans. Amer. Acad. Ophthal. Otolaryng., 51, 585.

WürdemanN, H. V. (1932). "Injuries of the Eye", 2nd ed., pp. 331-350. Kimpton, London. 